GUIDELINES

\title{
Guidelines for the management of inflammatory bowel disease in adults
}

\author{
M J Carter, A J Lobo, S P L Travis, on behalf of the IBD Section of the British Society of \\ Gastroenterology
}

\subsection{INTRODUCTION}

Ulcerative colitis (UC) and Crohn's disease (CD) (collectively termed inflammatory bowel disease (IBD)) are complex disorders reflected by wide variation in clinical practice. These guidelines, commissioned by the Clinical Services' Committee of the British Society of Gastroenterology (BSG) for clinicians and allied professionals caring for patients with IBD in the United Kingdom, provide an evidence based document describing good clinical practice for investigation and treatment. The guidelines are intended to bring consistency, but should not necessarily be regarded as the standard of care for all patients. Individual cases must be managed on the basis of all clinical data available for that case. Patient preferences should be sought and decisions jointly made between patient and health professional.

\subsection{Development of guidelines}

A comprehensive literature search was performed using electronic databases (Medline, PubMed, and Ovid; keywords: "inflammatory bowel disease", "ulcerative colitis", and "Crohn's disease") by Dr Carter. A preliminary document was drafted by Dr Carter, Dr Lobo, and contributing authors. This was summarised by Dr Travis and revised after circulation first to the committee and then to members of the IBD section of the BSG, before submission to the Clinical Services' Committee.

\subsection{Grading of recommendations ${ }^{1}$}

The guidelines conform to the North of England evidence based guidelines development project. The grading of each recommendation is dependent on the category of evidence supporting it:

- Grade $A$-requires at least one randomised controlled trial as part of a body of literature of overall good quality and consistency addressing the specific recommendation (evidence categories Ia and Ib).

- Grade B-requires the availability of clinical studies without randomisation on the topic of consideration (evidence categories IIa, IIb, and III).

- Grade C-requires evidence from expert committee reports or opinions or clinical experience of respected authorities, in the absence of directly applicable clinical studies of good quality (evidence category IV).

\subsection{Scheduled review of guidelines}

The content and evidence base for these guidelines should be revised within three years of publication, to take account of new evidence. We recommend that these guidelines are audited and request feedback from all users.

\subsection{SERVICE DELIVERY}

\subsection{Impact of IBD on patients and society ${ }^{2-4}$}

Patients find symptoms of UC or CD embarrassing and humiliating. IBD can result in loss of education and difficulty in gaining employment or insurance. It can also cause psychological problems and growth failure or retarded sexual development in young people. Medical treatments such as corticosteroids or immunosuppressive drugs cause secondary health problems, and surgery may result in complications such as impotence or intestinal failure.

The impact of IBD on society is disproportionately high, as presentation often occurs at a young age and has the potential to cause lifelong ill health. A hospital serving a population of 300000 would typically see 45-90 new cases per annum and have 500 under follow up, but many will be followed up in the community. There is a small increase in mortality for both UC (hazard ratio $1.44,95 \%$ CI 1.31 to 1.58 ) and CD (HR 1.73, CI 1.54 to 1.96), largely dependent on age and distribution of disease.

\subsection{Approach to care $^{5}$}

It is important to recognise the high calibre of care that can be delivered in smaller hospitals, because this is greatly valued by individual patients, but this is dependent on high quality training of clinicians working in this environment. Larger centres should support district general hospitals through multidisciplinary facilities for managing complex IBD. The nature of the symptoms and complexity of IBD mean that facilities are necessary beyond those normally provided for outpatients or inpatients. Measurable standards of care would assist the process of change in submissions to Primary Care Trusts and Strategic Health Authorities. As there has been little objective research in this area, criteria for standards are proposed, but arbitrary targets avoided:

- Rapid access to clinic appointments for patients with symptoms of IBD.

- Rapid access to advice and clinic appointments for patients in the event of a relapse.

- Adequate time and space in outpatients and wards to meet the unpredictable pattern of disease, allow discussion, explanation or counselling, and provide information or education material.

Abbreviations: 5-ASA, 5-aminosalicylic acid; AZA, azathioprine; CD, Crohn's disease; CRP, C reactive protein; CsA, cyclosporin; ESR, erythrocyte sedimentation rate; $F B C$, full blood count; IBD, inflammatory bowel disease; IFX, infliximab; MP, mercaptopurine; MTX, methotrexate; NNT, number needed to treat; TPMT, thiopurine methyl transferase; UC, ulcerative colitis. 
- Easy access to private, clean toilet facilities for patients both as outpatients and as inpatients.

- Administrative and clinical support for different models of care (hospital based, shared care systems with primary care, or patient managed care).

- A multidisciplinary team that manages patients with IBD in hospitals that train specialists in the care of IBD.

\subsection{Audit}

The above standards are appropriate topics to audit current provision of care. Many other aspects lend themselves to audit, including the availability of patient information, proportion and monitoring of patients on immunomodulator therapy, outcome of admission for severe colitis, time lost to work, cancer surveillance, or mortality.

\subsection{THE PATIENT'S PERSPECTIVE AND EXPECTATIONS}

\subsection{Understanding the patient's experience}

The following views have been expressed by the membership of the National Association for Colitis and Crohn's Disease. Patients recognise that desirable goals cannot always be met within resource constraints, but consider that demonstrable efforts should be made to achieve them.

- Someone with IBD should be seen as an individual and not be defined by their illness.

- Individuals differ in the way they choose to live with IBD. Views of "right" and "wrong" approaches to living with IBD are best avoided.

- Individuals often develop expertise about their own condition and needs which should be respected.

- Problems that cannot be solved by the healthcare team are best acknowledged and recognised as being impossible to solve, rather than ignored.

- Patients place a high value on sympathy, compassion, and interest.

- There should be equitable access to treatments and services and early referral of complex cases to specialist centres when local expertise is exceeded.

\subsection{Before diagnosis}

Delay in diagnosis is common and may be accompanied by dismissal of symptoms as due to stress. Two objectives would improve the situation:

- rapid access to hospital investigation;

- referral to a hospital that has a gastroenterologist who specialises in IBD.

\subsection{At diagnosis}

Patients want the emotional impact of the diagnosis to be taken into account, with several opportunities to discuss the implications and significance. Not all discussions need to be with the consultant. Objectives for care around the time of diagnosis include:

- the offer of suitable written information and audio-visual material;

- information about patient support groups and sources of help;

- an opportunity to meet a non-medical member of staff, such as a clinical nurse specialist or medical social worker familiar with IBD.

\subsection{Hospital management}

Individuals with IBD strongly believe that in addition to the above, the following should apply:

- sufficient information to make a rational personal choice about treatment options;

- close integration of medical and surgical management;

- straightforward access to support services, including dieticians, psychological support, and social workers;

- clearly stated management plans on discharge with well defined roles and responsibilities.

\subsection{Outpatient management}

Patients consider that the following should be central features:

- continuity of care, both in hospital and in primary care. Patients dislike seeing different individuals at each visit;

- a system that allows a choice about appropriate long term follow up;

- direct telephone access;

- attention to physical, emotional, and quality of life issues;

- help with problems related to insurance, employment, or social security.

\section{Recommendation}

3.5.1 That patient driven criteria be used as one criterion for auditing the quality of care at hospitals treating patients with inflammatory bowel diseases.

\subsection{INFLAMMATORY BOWEL DISEASE \\ 4.1 Definitions ${ }^{6-8}$}

Ulcerative colitis is characterised by diffuse mucosal inflammation limited to the colon. Disease extent can be broadly divided into distal and more extensive disease. "Distal" disease refers to colitis confined to the rectum (proctitis) or rectum and sigmoid colon (proctosigmoiditis). More extensive disease includes "left sided colitis" (up to the splenic flexure), "extensive colitis" (up to the hepatic flexure), and pancolitis (affecting the whole colon).

Crohn's disease is characterised by patchy, transmural inflammation, which may affect any part of the gastrointestinal tract. It may be defined by location (terminal ileal, colonic, ileocolic, upper gastrointestinal), or by pattern of disease (inflammatory, fistulating, or stricturing). These variables have been combined in the Vienna classification. About 5\% of patients with IBD affecting the colon are unclassifiable after considering clinical, radiological, endoscopic, and pathological criteria, because they have some features of both conditions. This can be termed indeterminate colitis (IC).

\subsection{Epidemiology 46910}

The incidence of UC is approximately 10-20 per 100000 per year with a reported prevalence of 100-200 per 100000 . The incidence remains stable, but the prevalence is likely to be an underestimate, because this implies an average disease duration (prevalence/incidence) of 10 years for a condition that is known to last for life. There are marked differences between ethnic groups with some (such as Ashkenazi Jews) having a particularly high incidence. The incidence of CD is around 5-10 per 100000 per year with a prevalence of 50-100 per 100000 ; the same considerations about 
underestimating prevalence apply. In contrast to UC however, the incidence of CD may be increasing. Both UC and CD are diseases of young people with a peak incidence between the ages of 10 and 40 years. They may, however, affect people of any age and 15\% of people are over the age of 60 at diagnosis. Up to 240000 people are affected by IBD in the UK.

\subsection{Pathogenesis"1}

The aetiologies of both UC and CD remain unknown. The consensus is that both diseases are a response to environmental triggers (infection, drugs, or other agents) in genetically susceptible individuals. The genetic component is stronger in CD than in UC. Smoking increases the risk of $\mathrm{CD}$, but decreases the risk of UC through unknown mechanisms.

Theories and evidence for pathogenetic mechanisms are too complex to be considered in this document. The broad areas examined are epidemiology, the gut/environmental interface, the inflammatory process, and genetics of each disease. Epidemiological studies have considered diet, drug, and vaccination history, seasonal variation, water supply, and social circumstances. The gut/environmental interface includes work on luminal bacteria, biofilms, the epithelial glycocalyx and mucus, epithelial barrier function, epithelial remodelling, and immune/epithelial interactions. The inflammatory process has been examined through cell signalling pathways, cytokine profiles, eicosanoid and other inflammatory mediators, lymphocyte trafficking, cell surface molecules, interactions between stromal and immune cells, and neuroimmune communication. Genetics have adopted a candidate gene approach, genome wide screening through microsatellite markers and, most recently, studies on functional gene expression. Mutations of one gene (CARD15/ NOD2), located on Chr 16, have been associated with small intestinal CD in white (but not oriental) populations. Two other genes (OCTN1 and 2 on Chr 5 and DLG5 on Chr 10) have recently been associated with $\mathrm{CD}$ but these need to be confirmed by independent studies. Other genes have yet to be identified, although their existence is strongly suggested by replicated linkage to a number of chromosomes.

\subsection{Clinical features and pattern of disease 12-16 $^{\text {12 }}$}

The cardinal symptom of UC is bloody diarrhoea. Associated symptoms of colicky abdominal pain, urgency, or tenesmus may be present. UC is a severe disease that used to carry a high mortality and major morbidity. With modern medical and surgical management, the disease now has a slight excess of mortality in the first two years after diagnosis, but little subsequent difference from the normal population. However, a severe attack of UC is still a potentially life threatening illness. The clinical course of UC is marked by exacerbation and remission. About $50 \%$ of patients with UC have a relapse in any year. An appreciable minority has frequently relapsing or chronic, continuous disease and, overall, $20-30 \%$ of patients with pancolitis come to colectomy. After the first year approximately $90 \%$ of patients are fully capable of work (defined by $<1$ month off work per year), although UC causes significant employment problems for a minority.

Symptoms of CD are more heterogeneous, but typically include abdominal pain, diarrhoea, and weight loss. Systemic symptoms of malaise, anorexia, or fever are more common with CD than UC. CD may cause intestinal obstruction due to strictures, fistulae (often perianal), or abscesses. Both ulcerative and Crohn's colitis are associated with an increased risk of colonic carcinoma. In CD surgery is not curative and management is directed to minimising the impact of disease. At least $50 \%$ of patients require surgical treatment in the first 10 years of disease and approximately $70-80 \%$ will require surgery within their lifetime. The overall mortality of CD is slightly higher than the normal population and is greatest in the 2 years after diagnosis or in those with upper gastrointestinal disease. The clinical course of CD is also characterised by exacerbations and remission. CD tends to cause greater disability than UC with only $75 \%$ of patients fully capable of work in the year after diagnosis and 15\% of patients unable to work after 5-10 years of disease.

\subsection{Diagnosis and investigation ${ }^{7}$ 17-19}

The diagnosis of IBD is confirmed by clinical evaluation and a combination of biochemical, endoscopic, radiological, histological, or nuclear medicine based investigations. In the case of UC the diagnosis should be made on the basis of clinical suspicion supported by appropriate macroscopic findings on sigmoidoscopy or colonoscopy, typical histological findings on biopsy, and negative stool examinations for infectious agents. For $\mathrm{CD}$ the diagnosis depends on demonstrating focal, asymmetric, and often granulomatous inflammation but the investigations selected vary according to the presenting manifestations, physical findings, and complications.

\subsubsection{History and examination}

A full history should include recent travel, medication, smoking, and family history. Details should include the stool frequency and consistency, urgency, rectal bleeding, abdominal pain, malaise, fever, weight loss, and symptoms of extraintestinal (joint, cutaneous, and eye) manifestations of IBD. General examination includes general wellbeing, pulse rate, blood pressure, temperature, checking for anaemia, fluid depletion, weight loss, abdominal tenderness or distension, palpable masses, and perineal examination.

\subsubsection{Initial investigations}

Laboratory investigations should include full blood count (FBC), U\&Es, liver function tests, and erythrocyte sedimentation rate (ESR) or C reactive protein (CRP), as well as microbiological testing for infectious diarrhoea including Clostridium difficile toxin. Additional tests may be needed for patients who have travelled abroad. Abdominal radiography is essential in the initial assessment of patients with suspected severe IBD: it excludes colonic dilatation and may help assess disease extent in UC or identify proximal constipation. In $\mathrm{CD}$ abdominal radiography may give an impression of a mass in the right iliac fossa, or show evidence of small bowel dilatation.

\subsubsection{Sigmoidoscopy}

For all patients presenting with diarrhoea, rigid sigmoidoscopy should be performed unless there are immediate plans to perform flexible sigmoidoscopy. Macroscopic features of UC are loss of the vascular pattern, granularity, friability, and ulceration of the rectal mucosa. A rectal biopsy is best taken for histology even if there are no macroscopic changes.

\subsubsection{Colonoscopy}

For mild to moderate disease, colonoscopy is usually preferable to flexible sigmoidoscopy, because the extent of disease can be assessed, but in moderate to severe disease there is a higher risk of bowel perforation and flexible sigmoidoscopy is safer. It is appropriate to defer investigations until the clinical condition improves. For suspected CD, colonoscopy to the terminal ileum and small bowel barium studies to define extent and site of disease are appropriate. A terminal ileal biopsy performed at colonoscopy documents the extent of examination and may find microscopic evidence of CD. 


\subsubsection{Other investigations}

Double contrast barium enema is usually inferior to colonoscopy because it does not allow mucosal biopsy and may underestimate the extent of disease. Small bowel radiology by follow through or intubation (small bowel enema) is the current standard for assessing the small intestine. Other conditions (including tuberculosis, Behcet's, lymphoma, vasculitis) may also cause ileal disease. The role of capsule endoscopy is at present unclear. White cell scanning is a safe, non-invasive investigation, but lacks specificity. Ultrasound in skilled hands is a sensitive and non-invasive way of identifying thickened small bowel loops in CD and may identify abscesses or free fluid in the peritoneum. Computed tomography and magnetic resonance imaging, especially of the perineum, help evaluate activity and complications of disease. Laparoscopy may be necessary in selected patients, especially where the differential diagnosis of intestinal tuberculosis is being considered.

\subsubsection{Assessment of disease extent}

After the diagnosis of UC or CD has been confirmed, the disease extent should be defined, because it determines the best route for therapy. For UC the extent is defined as the proximal margin of macroscopic inflammation, because this is most clearly related to the risk of complications, including dilatation and cancer. The implications of limited macroscopic disease with extensive microscopic inflammation remain unclear. For CD both small bowel and colon should be assessed.

\subsection{Histopathology 20}

Pathological examination of biopsy specimens should be carried out histologically according to the BSG document $A$ Structured Approach to Colorectal Biopsy Assessment (Guidelines in Gastroenterology No 9). There should be an attempt to define the type of IBD, to mention other co-existent diagnoses or complications, and to mention the presence or absence of dysplasia.

\subsection{Imaging ${ }^{21}$}

It is desirable that clinicians discuss imaging with an appropriate radiologist, to avoid unnecessary exposure to ionising radiation. There should be a forum to review the results of imaging in the context of the clinical history so that appropriate management can be planned.

\subsection{Drugs used in the treatment of IBD}

Therapy for IBD is a rapidly evolving field, with many new biological agents under investigation that are likely to change therapeutic strategies radically in the next decade. Details of the principal drugs can only be summarised in this document.

\subsubsection{Aminosalicylates 22}

(Including mesalazine or 5-aminosalicylic acid (5-ASA), "mesalamine" in the USA.) Different formulations deliver millimolar concentrations to the gut lumen. Aminosalicylates are available as oral tablets, sachets or suspension, liquid or foam enemas, or suppositories. They act on epithelial cells by a variety of mechanisms to moderate the release of lipid mediators, cytokines, and reactive oxygen species. Oral forms include:

- $\mathrm{pH}$ dependent release/resin coated (Asacol, Salofalk, or Ipocol, Mesren);

- time controlled release (Pentasa);

- delivery by carrier molecules, with release of 5-ASA after splitting by bacterial enzymes in the large intestine (sulphasalazine (Salazopyrin), olsalazine (Dipentum), balsalazide (Colazide)).

\section{Maintaining remission ${ }^{23-27}$}

The main role for 5-ASA is maintenance of remission in UC. All 5-ASA derivatives show comparable efficacy to sulphasalazine, but in a meta-analysis the parent compound had a modest therapeutic advantage for maintaining remission (odds ratio 1.29, confidence interval 1.08 to 1.57). The choice of 5-ASA is debated, but is influenced by tolerability (mesalazine is tolerated by $80 \%$ of those unable to tolerate sulphasalazine), dose schedule (twice daily dosing is associated with better compliance) and cost. Efficacy may depend more on adherence with the prescribed dose than the delivery system. If the delivery system is considered important, then the drug is best matched to the site of disease, by using azobonded compounds for distal disease. Maintenance therapy with all 5-ASA drugs may reduce the risk of colorectal cancer by up to $75 \%$ (OR 0.25 , CI 0.13 to 0.48 ). This favours long term treatment for patients with extensive UC. 5-ASA is less effective for maintaining remission in CD. Mesalazine $>2 \mathrm{~g} /$ day reduces relapse after surgery $(\mathrm{NNT}=8)$, especially after small bowel resection ( $40 \%$ reduction at 18 months). It is ineffective after steroid induced remission, except for those at high risk of relapse given $4 \mathrm{~g}$ /day (relapse risk on placebo 2.0, CI 1.0 to 3.8 ).

\section{Active disease ${ }^{2528-31}$}

Higher doses of 5-ASA (4 g/day) are more effective than placebo for inducing remission in mild UC or CD. For ulcerative colitis, greater clinical improvement (but not necessarily remission) is associated with doses $\geqslant 3 \mathrm{~g} /$ day. Clinical improvement characteristically occurs at twice the remission rate. In a meta-analysis of oral 5-ASA for active UC, of 19 trials involving 2032 patients, nine were placebo controlled and 10 compared mesalazine with sulphasalazine. The outcome of interest on an intention to treat principle was the failure to induce remission, so that a pooled odds ratio $<1.0$ indicates one treatment to be more effective than another. Mesalazine was more than twice as effective as placebo (OR 0.39; CI 0.29 to 0.52 , but not significantly better than sulphasalazine (OR 0.87 ; CI 0.63 to 1.20 ). In active Crohn's ileocolitis, a meta-analysis of the three placebo controlled trials of Pentasa $4 \mathrm{~g}$ daily for 16 weeks in a total of 615 patients, showed a mean reduction of the CDAI from baseline of -63 points, compared with -45 points for placebo $(p=0.04)$. While this confirms that Pentasa $4 \mathrm{~g} /$ day is superior to placebo in reducing CDAI, the clinical significance is not clear. Subgroup analyses do not provide sufficiently clear answers to whether one group of patients benefit more than another.

\section{Adverse effects of 5-ASA ${ }^{32-34}$}

Side effects of sulphasalazine occur in $10-45 \%$, depending on the dose. Headache nausea, epigastric pain, and diarrhoea are most common and dose related. Serious idiosyncratic reactions (including Stevens Johnson syndrome, pancreatitis, agranulocytosis, or alveolitis) are rare. Mesalazine intolerance occurs in up to $15 \%$. Diarrhoea $(3 \%)$, headache $(2 \%)$, nausea $(2 \%)$, and rash $(1 \%)$ are reported, but a systematic review has confirmed that all new 5-ASA agents are safe, with adverse events that are similar to placebo for mesalazine or olsalazine. No comparison between balsalazide and placebo has been published, but events were lower than with sulphasalazine. Acute intolerance in 3\% may resemble a flare of colitis as it includes bloody diarrhoea. Recurrence on rechallenge provides the clue. Renal impairment (including interstitial nephritis and nephrotic syndrome) is rare and 
idiosyncratic. A population based study found the risk (OR 1.60, CI 1.14 to 2.26 compared with normal) to be associated with disease severity rather than the dose or type of mesalazine. Patients with pre-existing renal impairment, other potentially nephrotoxic drugs, or comorbid disease should have renal function monitored during 5-ASA therapy.

\subsubsection{Corticosteroids}

(Oral prednisolone, prednisone, budesonide (among others), or intravenous hydrocortisone, methylprednisolone.) Topical suppositories, foam or liquid enemas include hydrocortisone, prednisolone metasulphobenzoate, betamethasone, budesonide). Many strategies attempt to maximise topical effects while limiting systemic side effects of steroids. Budesonide (Entocort, Budenofalk) is a poorly absorbed corticosteroid with limited bioavailability and extensive first pass metabolism that has therapeutic benefit with reduced systemic toxicity in ileocaecal CD, or UC.

\section{Choice and mechanism ${ }^{35} 36$}

Corticosteroids are potent anti-inflammatory agents for moderate to severe relapses of both UC and CD. They have no role in maintenance therapy for either disease. They act through inhibition of several inflammatory pathwayssuppressing interleukin transcription, induction of I $\kappa \mathrm{B}$ that stabilises the NFKB complex, suppression of arachidonic acid metabolism, and stimulation of apoptosis of lymphocytes within the lamina propria of the gut.

\section{Efficacy for active UC $\mathrm{C}^{37-39}$}

Trials are all over 30 years old, but results are consistent. Oral prednisolone (starting at $40 \mathrm{mg}$ daily) induced remission in $77 \%$ of 118 patients with mild to moderate disease within 2 weeks, compared with $48 \%$ treated with 8 g/day sulphasalazine. A combination of oral and rectal steroids is better than either alone. Adverse events are significantly more frequent at a dose of $60 \mathrm{mg} /$ day compared with $40 \mathrm{mg} /$ day, without added benefit, so $40 \mathrm{mg}$ appears optimal for outpatient management of acute UC. Too rapid reduction can be associated with early relapse and doses of prednisolone $\leqslant 15 \mathrm{mg}$ day are ineffective for active disease.

\section{Efficacy for active $C D^{31}$ 40-42}

Two major trials established corticosteroids as effective therapy for inducing remission in CD. The National Cooperative Crohn's Disease Study randomised 162 patients, achieving $60 \%$ remission with $0.5-0.75 \mathrm{mg} / \mathrm{kg} /$ day prednisone (the higher dose for more severe disease) and tapering over 17 weeks, compared with $30 \%$ on placebo $(\mathrm{NNT}=3)$. The comparable European Co-operative Crohn's Disease Study on 105 patients achieved 83\% remission on prednisone $1 \mathrm{mg} / \mathrm{kg} /$ day compared with $38 \%$ on placebo $(\mathrm{NNT}=2)$ over 18 weeks. The high placebo response rate should be noted, because disease activity in Crohn's (and UC) fluctuates spontaneously. No formal dose response trial has been performed, but $92 \%$ remission within 7 weeks was achieved in 142 patients with moderately active Crohn's given prednisone $1 \mathrm{mg} / \mathrm{kg} /$ day with no tapering. Budesonide is slightly less effective than prednisolone, but is an appropriate alternative for active for active ileo-ascending colonic disease.

\section{Deciding to treat with steroids ${ }^{42}$}

Efficacy should be balanced against side effects, but decisive treatment of active disease in conjunction with a strategy for complete withdrawal of steroids is often appreciated by a patient suffering miserable symptoms. Regimens of steroid therapy vary between centres. A standard weaning strategy helps identify patients who relapse rapidly or do not respond and need adjunctive therapy with thiopurines or as an inpatient.

\section{Adverse effects of steroids}

Three broad groups can be identified, although 50\% of patients report no adverse event. Early effects due to supraphysiological doses include cosmetic (acne, moon face, oedema), sleep and mood disturbance, dyspepsia, or glucose intolerance. Effects associated with prolonged use (usually $>12$ weeks, but sometimes less) include posterior subcapsular cataracts, osteoporosis, osteonecrosis of the femoral head, myopathy, and susceptibility to infection. Effects during withdrawal include acute adrenal insufficiency (from sudden cessation), a syndrome of myalgia, malaise, and arthralgia (similar to recrudesence of CD), or raised intracranial pressure. Complete steroid withdrawal is facilitated by early introduction of azathioprine, adjuvant nutritional therapy, or timely surgery.

\subsubsection{Thiopurines ${ }^{43}$}

(Azathioprine (AZA) and mercaptopurine (MP), unlicensed therapy for IBD.) Purine antimetabolites inhibit ribonucleotide synthesis, but the mechanism of immunomodulation is by inducing $\mathrm{T}$ cell apoptosis by modulating cell (Racl) signalling. Azathioprine is metabolised to mercaptopurine and subsequently to 6-thioguanine nucleotides. $\mathrm{T}(\mathrm{h})$ ioguanine has been used for treatment of IBD, but caution is appropriate because of potential hepatotoxicity.

\section{Efficacy $^{44-49}$}

Thiopurines are effective for both active disease and maintaining remission in $\mathrm{CD}$ and UC. A Cochrane review of the efficacy of AZA and MP for inducing remission in active CD demonstrated a benefit for thiopurine therapy compared with placebo with an odds ratio of 2.36 (95\% CI 1.57 to 3.53). This equates to a number needed to treat (NNT) of 5 and a number needed to harm (NNH) of 14. Their efficacy at maintaining remission is confirmed in another Cochrane review (OR 2.16 (CI 1.35 to 3.47), NNT $=7$ ). Thiopurines are effective as maintenance therapy for CD for up to 4 years. In a prospective trial, 83 patients with $\mathrm{CD}$ who had been in remission for 3.5 years on AZA were randomised to continue AZA or placebo and followed for 18 months. Relapse rates were $21 \%$ and $8 \%$ in placebo and AZA groups respectively $(p=0.0195)$. Practical advice for patients with either CD or UC who are started on AZA is to continue treatment for 3-4 years and then stop, except in those with evidence of continuing disease activity. For the $20 \%$ who relapse, AZA can be restarted and continued. No direct comparisons of the efficacy of AZA and MP in IBD exist. Some patients who are intolerant of AZA may tolerate MP.

\section{Indications for thiopurines $s^{44} 45$}

The main role for thiopurines is steroid sparing $(\mathrm{NNT}=3)$. For arbitrary, but practical, purposes this also applies to UC. Thiopurines should be considered for patients who require two or more corticosteroid courses within a calendar year; those whose disease relapses as the dose of steroid is reduced below $15 \mathrm{mg}$; relapse within 6 weeks of stopping steroid steroids; or postoperative prophylaxis of complex (fistulating or extensive) CD.

\section{Dosing}

Tailoring or optimisation of thiopurine therapy can occur before or during treatment. Clinicians should aim for a maintenance dose of AZA of $2-2.5 \mathrm{mg} / \mathrm{kg} / \mathrm{day}$ and 6-MP of $1-1.5 \mathrm{mg} / \mathrm{kg} /$ day in both UC and CD. The "maximum" dose will differ between individuals and effectively means that level at which leucopenia develops. Leucopenia is a 
myelotoxic side effect of thiopurines and the metabolic phenotype of the individual can be defined by measuring thiopurine methyl transferase (TPMT) activity or the TPMT genotype.

Is measurement of TPMT necessary? $?^{50-52}$

Patients with leukaemia who are TPMT deficient are at increased risk of myelotoxicity. This does not necessarily apply in IBD. In one study the majority $(77 \%)$ of 41 IBD patients with AZA induced bone marrow suppression did not carry a TPMT mutation. Evidence that TPMT activity predicts other side effects or outcome is limited. It cannot yet be recommended as a prerequisite to therapy, because decades of experience has shown clinical AZA to be safe in UC or CD.

\section{Monitoring thiopurine therapy}

Manufacturers recommend weekly FBCs for the first 8 weeks of therapy followed by blood tests at least every 3 months. There is no evidence that this is effective. Less frequent monitoring (within 4 weeks of starting therapy and every 6-12 weeks thereafter) may be sufficient. It is just as important to advise patients to report promptly should a sore throat or other sign of infection occur.

\section{Side effects ${ }^{44} 454852-56$}

The most common cause of intolerance (affecting up to $20 \%$ ) are flu-like symptoms (myalgia, headache, diarrhoea) that characteristically occur after 2-3 weeks and cease rapidly when the drug is withdrawn. Profound leucopenia can develop suddenly and unpredictably in between blood tests, although it is rare (around 3\%). Hepatotoxicity and pancreatitis are uncommon $(<5 \%)$. Although azathioprine is the best agent for maintaining remission, 28\% of 622 patients experienced side effects. Fortunately when the drug is tolerated for 3 weeks, long term benefit can be expected. Thiopurines can reasonably be continued during pregnancy if UC or CD has been refractory. In a study of 155 men and women with IBD who were parents of 347 pregnancies while taking MP there was no difference in miscarriage, congenital abnormality, or infection rate in the thiopurine group compared with a control group. The risk of malignancy related to thiopurine is at best small. Large audits of up to 755 patients have shown no increased risk of lymphoma or other cancers in IBD patients treated with AZA. A primary care prescribing database study of nearly 1500 IBD patients who received at least one prescription of AZA/6-MP also showed no overall risk (relative risk 1.6 (95\% CI 0.1 to 8.8$)$ ) of lymphoma but little is known about the duration or dose of therapy of this cohort. Decision analysis suggests that the benefits of AZA outweigh any risk of lymphoma in IBD.

\subsubsection{Methotrexate M $^{57}$}

(Oral, subcutaneous or intramuscular injection, unlicensed therapy for IBD.) Polyglutamated metabolites of methotrexate inhibit dihydrofolate reductase, but this cytotoxic effect does not explain its anti-inflammatory effect. Inhibition of cytokine and eicosanoid synthesis probably contribute.

\section{Efficacy $^{57-59}$}

Methotrexate (MTX) is effective for inducing remission or preventing relapse in CD. At present, the role of MTX is in the treatment of active or relapsing $\mathrm{CD}$ in those refractory to or intolerant of AZA or MP. In a controlled study, 141 steroid dependent patients were randomised to either $25 \mathrm{mg} /$ week of intramuscular MTX or placebo for 16 weeks, with a concomitant daily dose of prednisolone (20 $\mathrm{mg}$ at initiation) that was reduced over a 3 month period. More patients in the MTX treated group were able to withdraw steroids and enter remission compared with placebo $(39 \% v 19 \% ; \mathrm{p}=0.025)$. It is effective for preventing relapse after remission has been induced by MTX. MTX was superior to placebo in 76 patients randomised to $15 \mathrm{mg} /$ week of MTX or placebo for 9 months $(65 \% v 39 \%$ in remission at week $40 ; \mathrm{p}=0.04)$. The need for steroids was reduced $(p=0.01)$. No comparable trials have addressed the role of MTX in the induction or maintenance of remission in UC.

Dose, delivery, and duration ${ }^{57} 60$

Unlike rheumatoid arthritis, doses of $<15 \mathrm{mg} /$ week are ineffective for CD and $25 \mathrm{mg} /$ week is standard. For practical reasons relating to the reconstitution of parenteral cytotoxic drugs, oral dosing is most convenient, although parenteral administration may be more effective. Subcutaneous administration may be reserved for patients with small intestinal CD who do not absorb oral MTX. Duration of therapy is debated. The 3 year remission rate for methotrexate in one series was $51 \%$, which compares with data on azathioprine from the same centre $(69 \% 3$ year remission rate for azathioprine).

\section{Monitoring therapy}

Measurement of full blood count and liver function tests are advisable before and within 4 weeks of starting therapy, then monthly. The same caveats as for monitoring thiopurine therapy apply. Patients should remain under specialist follow up.

\section{Side effects ${ }^{57} 61$}

Early toxicity from methotrexate is primarily gastrointestinal (nausea, vomiting, diarrhoea, and stomatitis) and this may be limited by co-prescription of folic acid $5 \mathrm{mg}$ two or three days apart from the MTX. Treatment is discontinued in $10-18 \%$ of patients because of side effects. The principal concerns are hepatotoxicity and pneumonitis. A study of liver biopsies in IBD patients taking MTX showed mild histological abnormalities, despite cumulative doses of up to $5410 \mathrm{mg}$. Surveillance liver biopsy is not warranted, but if the AST doubles then it is sensible to withhold MTX until it returns to normal, before a rechallenge. The prevalence of pneumonitis has been estimated at two to three cases per 100 patient years of exposure, but large series have not reported any cases.

\subsubsection{Ciclosporin 62}

(Oral or intravenous, unlicensed therapy for UC.) Ciclosporin (CsA) is an inhibitor of calcineurin, preventing clonal expansion of $\mathrm{T}$-cell subsets. It has a rapid onset of action and is effective in the management of severe UC.

\section{Role of $C_{s} A^{62-68}$}

Intravenous CsA is rapidly effective as a salvage therapy for patients with refractory colitis, who would otherwise face colectomy, but its use is controversial because of toxicity and long term failure rate. Toxicity can be reduced by using lower doses $(2 \mathrm{mg} / \mathrm{kg} /$ day intravenously), by oral microemulsion ciclosporin, or by monotherapy without corticosteroids. The drug should rarely be continued for more than 3-6 months and its main role is a bridge to thiopurine therapy. A metaanalysis of four randomised controlled trials showed that CsA has no therapeutic value in CD.

\section{Monitoring therapy ${ }^{62}$}

Measurement of blood pressure, full blood count, renal function, and CsA concentration (aim 100-200 ng/ml) are advisable at 0,1 , and 2 weeks, then monthly. Measurement of blood cholesterol and magnesium are appropriate before starting therapy (below). 
Side effects ${ }^{62} 6465$

Minor side effects occur in 31-51\%, including tremor, paraesthesiae, malaise, headache, abnormal liver function, gingival hyperplasia, and hirsutism. Major complications are reported in $0-17 \%$, including renal impairment, infections, and neurotoxicity. The risk of seizures is increased in patients with a low cholesterol $(<3.0 \mathrm{mmol} / \mathrm{l})$ or magnesium $(<0.50 \mathrm{mmol} / \mathrm{l})$. Oral therapy is an alternative in these circumstances. Prophylaxis against Pneumocystis carinii pneumonia is an individual decision dependent on nutritional state, concomitant immunomodulator therapy, and duration of therapy, but other opportunistic infections (for example, Aspergillus sp.) may be as common.

\subsubsection{Infliximab 69}

Infliximab (IFX) (Remicade) is a chimeric anti-TNF monoclonal antibody with potent anti-inflammatory effects, possibly dependent on apoptosis of inflammatory cells. Numerous controlled trials have demonstrated efficacy in both active and fistulating CD. Guidelines for the use of infliximab have been produced by the National Institute of Clinical Excellence (www.nice.org.uk, guideline no 40).

\section{Efficacy for inflammatory $C D^{69-71}$}

A multicentre, double blind study in 108 patients with moderate to severe CD refractory to 5-ASA, corticosteroids, and/or immunomodulators, demonstrated an $81 \%$ response rate at 4 weeks after $5 \mathrm{mg} / \mathrm{kg}$ IFX compared with $17 \%$ given placebo. The duration of response varied, but $48 \%$ who had received $5 \mathrm{mg} / \mathrm{kg}$ still had a response at week 12. The ACCENT-1 study was the definitive retreatment trial. Maintenance of remission in 335 responders to a single infusion of IFX $5 \mathrm{mg} / \mathrm{kg}$ for active CD (out of an initial 573) was examined. The protocol was complex. In broad terms, patients were treated with placebo, $5 \mathrm{mg} / \mathrm{kg}$ or $10 \mathrm{mg} / \mathrm{kg}$ every 8 weeks until week 46 . At week $30,21 \%$ of the placebo treated patients were in remission compared with $39 \%$ of the patients treated with $5 \mathrm{mg} / \mathrm{kg}$ infusions $(\mathrm{p}=0.003)$ and $45 \%$ of those treated with $10 \mathrm{mg} / \mathrm{kg}$ infusions $(\mathrm{p}=0.0002)$. IFX is licensed but not yet approved by NICE for maintenance therapy of CD in the UK.

\section{Evidence for fistulising $C D^{72} 7^{73}$}

IFX is the first agent to show a therapeutic effect for fistulising $C D$ in a controlled trial. Ninety four patients with draining abdominal or perianal fistulas of at least 3 months' duration were treated. $68 \%$ in the $5 \mathrm{mg} / \mathrm{kg}$ group and $56 \%$ in the $10 \mathrm{mg} / \mathrm{kg}$ group experienced a $50 \%$ reduction in the number of draining fistulas at two or more consecutive visits compared with $26 \%$ given placebo $(\mathrm{p}=0.002$ and $\mathrm{p}=0.02$, respectively). The problem is that the duration of this effect was in most cases limited to only 3 or 4 months. A large retreatment trial for fistulating CD (ACCENT-II) has been conducted. A total of 306 patients with actively draining enterocutaneous fistulae were treated with three induction infusions of IFX $5 \mathrm{mg} / \mathrm{kg}$ at weeks 0,2 , and 6. Of the 306, 195 $(69 \%)$ responded and these were randomised to $5 \mathrm{mg} / \mathrm{kg}$ maintenance infusions or placebo every 8 weeks. Patients who lost response were switched from placebo to active treatment at $5 \mathrm{mg} / \mathrm{kg}$, or the retreatment dose increased from 5 to $10 \mathrm{mg} / \mathrm{kg}$. At the end of the 12 month trial, $46 \%$ of the patients on active retreatment had a fistula response versus $23 \%$ on placebo $(p=0.001)$. Complete response (all fistulae closed) was observed in $36 \%$ of patients on active treatment, compared with $19 \%$ on placebo $(p=0.009)$. Treatment of fistulising CD with IFX is not currently approved by NICE unless criteria for severe active disease are also met.
Selection $^{69}$

National guidelines govern its use. In the UK, it is limited to patients with severe active CD (Harvey Bradshaw index $>8$, CD activity index $>300$ ) refractory to or intolerant of steroids and immunosuppression, for whom surgery is inappropriate. Retreatment is often necessary, after a variable interval (most commonly 8-16 weeks). All patients should receive an immunomodulator (AZA, MP, or MTX) unless these cannot be tolerated, as these probably extend the interval and reduce development of antibodies to IFX that in turn reduce efficacy and increase side effects. Because IFX is associated with a four- or fivefold increase in risk of tuberculosis, all patients should have a chest $x$ ray to exclude past or present infection and be asked about previous BCG vaccination before IFX infusion. Tuberculin testing can be limited to those who have not had BCG and who are not on immunomodulators. Patients with evidence of previous tuberculosis should be seen by a thoracic physician. Guidelines for chemoprophylaxis are being produced by the British Thoracic Society (2004).

\section{Side effects ${ }^{74} 75$}

Treatment with IFX is relatively safe if used for appropriate indications. Infusion reactions (during or shortly after infusion) are rare and respond to slowing the infusion rate or treatment with antihistamines, paracetamol, and sometimes corticosteroids. Anaphylactic reactions have been reported. A delayed reaction of joint pain and stiffness, fever, myalgia, and malaise may occur if there has been an interval $>1$ year following a previous infusion and can be limited by pretreatment with hydrocortisone. Infection is the main concern. Active sepsis (for example, an abscess) is an absolute contraindication, as this risks overwhelming septicaemia. Reactivation or development of tuberculosis has been reported in 24/100 000 patients with rheumatoid arthritis given anti-TNF therapy, compared with 6/100 000 not given such treatment. IFX may exacerbate existing cardiac failure. The theoretical risk of lymphoproliferative disorders or malignancy (in view of the role of endogenous TNF in tumour suppression) has not been confirmed in postmarketing surveillance, but follow up is short. IFX is best avoided in those with a history of malignancy.

\subsection{MEDICAL MANAGEMENT OF ULCERATIVE COLITIS}

Therapeutic decisions depend on disease activity and extent. Disease activity is best evaluated objectively using a clinical activity index (the Truelove \& Witts ${ }^{\prime 18}$ or the Simple Clinical Colitis $^{19}$ indices are recommended). Patients with severe disease require hospital admission, whereas those with mild/ moderate disease can generally be managed as outpatients.

Disease extent can broadly be divided into distal and more extensive disease. Topical management is appropriate for some patients with active disease. This is usually the case for those with proctitis and often the case if the disease extends into the sigmoid. For those with more extensive disease, oral or parenteral therapy are the mainstays of treatment, although some of these patients may get additional benefit from topical therapy.

\subsection{Active left sided or extensive UC22 $2832 \quad 37-394776$}

For the purposes of these guidelines, "left sided" disease is defined as disease extending proximal to the sigmoid descending junction up to the splenic flexure and "extensive" UC as extending proximal to the splenic flexure. Disease activity should be confirmed by sigmoidoscopy and infection excluded, although treatment need not wait for microbiological analysis. 
For the treatment of active, left sided, or extensive UC:

- Mesalazine 2-4 g daily or balsalazide $6.75 \mathrm{~g}$ daily are effective first line therapy for mild to moderately active disease (grade $A$ ).

- Olsalazine $1.5-3 \mathrm{~g}$ daily has a higher incidence of diarrhoea in pancolitis (grade A) and is best for patients with left sided disease, or intolerance of other 5-ASA.

- Sulphasalazine has a higher incidence of side effects compared with newer 5-ASA drugs (grade A). Selected patients, such as those with a reactive arthropathy, may benefit.

- Prednisolone $40 \mathrm{mg}$ daily is appropriate for patients in whom a prompt response is required, or those with mild to moderately active disease, in whom mesalazine in appropriate dose has been unsuccessful (grade B).

- Prednisolone should be reduced gradually according to severity and patient response, generally over 8 weeks. More rapid reduction is associated with early relapse (grade C).

- Long term treatment with steroids is undesirable. Patients with chronic active steroid dependent disease should be treated with azathioprine $1.5-2.5 \mathrm{mg} / \mathrm{kg} / \mathrm{day}$ or mercaptopurine $0.75-1.5 \mathrm{mg} / \mathrm{kg} /$ day (grade $A$ ).

- Topical agents (either steroids or mesalazine) may be added to the above agents. Although they are unlikely to be effective alone, they may benefit some patients with troublesome rectal symptoms (grade B).

- Ciclosporin may be effective for severe, steroid refractory colitis (grade A) (see section 5.3).

\section{Recommendations}

5.1.1 Active left sided or extensive ulcerative colitis should be treated with oral aminosalicylates or corticosteroids to give prompt relief of symptoms, after the different options have been discussed and the views of the patient taken into account.

5.1.2 There is insufficient evidence to recommend the use of other agents outside trials or specialist centres.

\subsection{Active distal UC ${ }^{28}$ 77-81}

The term "distal colitis" applies to disease up to the sigmoid descending junction, including "proctitis", meaning disease limited to the rectum. Patient preference has a greater influence on management than for extensive colitis, in view of the option of topical or systemic therapy. Choice of topical formulation should be determined by the proximal extent of the inflammation (suppositories for disease to the rectosigmoid junction, foam or liquid enemas for more proximal disease) along with patient preference, such as ease of insertion or retention of enemas.

For the treatment of active, distal UC:

- In mild to moderate disease, topical mesalazine $1 \mathrm{~g}$ daily (in appropriate form for extent of disease) combined with oral mesalazine 2-4 g daily, olsalazine 1.5-3 g daily, or balsalazide $6.75 \mathrm{~g}$ daily, are effective first line therapy (grade $A$ ).

- Topical corticosteroids are less effective than topical mesalazine, and should be reserved as second line therapy for patients who are intolerant of topical mesalazine (grade A).

- Patients who have failed to improve on a combination of oral mesalazine with either topical mesalazine or topical corticosteroids should be treated with oral prednisolone $40 \mathrm{mg}$ daily. Topical agents may be used as adjunctive therapy in this situation (grade $A$ ).

- Prednisolone should be reduced gradually according to severity and patient response, generally over 8 weeks (grade C).

- Sulphasalazine 2-4 g daily has a higher incidence of side effects compared with newer 5-ASA drugs (grade A). Selected patients, such as those with a reactive arthropathy, may benefit.

- Topical mesalazine alone or oral mesalazine alone are effective, but less effective than combination therapy, so combination therapy is appropriate (grade B).

- Proximal constipation should be treated with stool bulking agents or laxatives (grade $C$ ).

\section{Recommendations}

5.2.1 Active distal colitis should be treated with topical mesalazine or topical steroid combined with oral mesalazine or corticosteroids to give prompt relief of symptoms.

5.2.2 There is insufficient evidence to recommend the use of other agents.

\subsection{Severe UC $62-66$ 82-86}

Patients who have failed to respond to maximal oral treatment with a combination of mesalazine and/or steroids with or without topical therapy, or those who present with severe disease defined by the Truelove and Witts' criteria $^{18}$ should be admitted for intensive intravenous therapy (below). Monitoring of pulse rate, stool frequency, $\mathrm{C}$ reactive protein, and plain abdominal radiograph help identify those who need colectomy. Close liaison with a surgeon who specialises in the management of patients with UC should be maintained. Acute onset UC is sometimes difficult to distinguish from infective colitis, but treatment with corticosteroids should not be delayed until stool microbiology results are available.

The approach to treatment of severe UC involves:

- Physical examination daily to evaluate abdominal tenderness and rebound tenderness. Joint medical and surgical management is appropriate.

- Recording of vital signs four times daily and more often if deterioration noted.

- A stool chart to record number and character of bowel movements, including the presence or absence of blood and liquid versus solid stool.

- Measurement of FBC, ESR, or CRP, serum electrolytes, serum albumin, and liver function tests every 24-48 hours.

- Daily abdominal radiography if colonic dilatation (transverse colon diameter $\geqslant 5.5 \mathrm{~cm}$ ) is detected at presentation. If not dilated, there should be a low threshold for further radiological assessment if there is clinical deterioration.

- Intravenous fluid and electrolyte replacement to correct and prevent dehydration or electrolyte imbalance, with blood transfusion to maintain a haemoglobin $>10 \mathrm{~g} / \mathrm{dl}$

- Subcutaneous heparin to reduce the risk of thromboembolism (grade B).

- Nutritional support (by enteral or parenteral route) if the patient is malnourished (grade C). 
- Intravenous corticosteroids (hydrocortisone $400 \mathrm{mg} / \mathrm{day}$ or methylprednisolone $60 \mathrm{mg} /$ day) (grade B). Higher doses of steroids offer no greater benefit, but lower doses are less effective (grade A).

- Withdrawal of anticholinergic, antidiarrhoeal agents, NSAID and opioid drugs, which risk precipitating colonic dilatation (grade B).

- Continuation of aminosalicylates once oral intake resumes, although these have not been studied in severe disease (grade $C)$.

- Topical therapy (corticosteroids or mesalazine) if tolerated and retained, although there have been limited studies in acute severe disease (grade $C$ ).

- Intravenous antibiotics only if infection is considered, or immediately before surgery (grade C). Controlled trials of intravenous metronidazole and oral vancomycin in acute severe UC have shown no significant benefit (grade A).

- Immediate surgical referral if there is evidence of toxic megacolon (diameter $>5.5 \mathrm{~cm}$, or caecum $>9 \mathrm{~cm}$ ). The urgency with which surgery is undertaken after recognition of colonic dilatation depends on the condition of the patient: the greater the dilatation and the greater the degree of systemic toxicity, the sooner surgery should be undertaken, but signs may be masked by steroid therapy (grade $C$ ). In selected patients with mild dilatation, expectant management may be undertaken. Any clinical, laboratory, or radiological deterioration mandates immediate colectomy (grade C).

- Objective re-evaluation on the third day of intensive treatment. A stool frequency of $>8 /$ day or CRP $>45 \mathrm{mg} / \mathrm{l}$ at 3 days appears to predict the need for surgery in $85 \%$ of cases. Surgical review and input from specialist colorectal nurse or stomatherapist is appropriate at this stage. There is no benefit from intravenous steroids beyond 7-10 days (grade B).

- Consideration of colectomy or intravenous ciclosporin $2 \mathrm{mg} / \mathrm{kg} /$ day if there is no improvement during the first 3 days (grade $A$ ). Following induction of remission, oral ciclosporin for 3-6 months is appropriate (grade B). Intravenous ciclosporin alone may be as effective as methylprednisolone, but potential side effects mean that it is rarely an appropriate single first line therapy (grade $A)$.

\section{Recommendations}

5.3.1 Severe ulcerative colitis should be managed jointly by a gastroenterologist in conjunction with a colorectal surgeon.

5.3.2 Patients should be kept informed of treatment and prognosis, including a 25-30\% chance of needing colectomy.

5.3.3 Further controlled trials should be conducted in the medical treatment of severe ulcerative colitis.

\subsection{Maintenance of remission 22-24 323447525477 87-89}

Lifelong maintenance therapy is generally recommended for all patients, especially those with left sided or extensive disease, and those with distal disease who relapse more than once a year. Discontinuation of medication may be reasonable for those with distal disease who have been in remission for 2 years and are averse to such medication. However, there is some evidence that maintenance therapy reduces the risk of colorectal cancer.

For the maintenance of remission in UC:

- Oral mesalazine 1-2 g daily or balsalazide $2.5 \mathrm{~g}$ daily should be considered as first line therapy (grade $A$ ).

- Sulphasalazine 2-4 g daily has a higher incidence of side effects compared with newer 5-ASA drugs (grade A).

- Selected patients, such as those with a reactive arthropathy, may benefit.

- Olsalazine 1.5-3 g daily has a higher incidence of diarrhoea in pancolitis (grade $A$ ) and is best for patients with left sided disease, or intolerance of other 5-ASA.

- Topical mesalazine $1 \mathrm{~g}$ daily may be used in patients with distal disease with/without oral mesalazine, but patients are less likely to be compliant (grade A).

- All aminosalicylates have been associated with nephrotoxicity, which appears both to be idiosyncratic and in part dose related. Reactions are rare, but patients with preexisting renal disease are at higher risk. Occasional (perhaps annual) measurement of creatinine is sensible, although there is no evidence that monitoring is necessary or effective. Aminosalicylates should be stopped if renal function deteriorates (grade $C$ ).

- Most patients require lifelong therapy, although some patients with very infrequent relapses (especially if with limited extent of disease) may remain in remission on no maintenance therapy (grade $C$ ).

- The advantages and disadvantages of continued treatment with aminosalicylates are best discussed with the patient, especially if a patient has been in remission for a substantial length of time (>2 years) (grade B).

- Steroids are ineffective at maintaining remission (grade $A$ ).

- Azathioprine $1.5-2.5 \mathrm{mg} / \mathrm{kg} / \mathrm{day}$ or mercaptopurine $0.75-1.5 \mathrm{mg} / \mathrm{kg} /$ day (see also section 6.5 ) are effective at maintaining remission in UC (grade A). However, in view of toxicity they should be reserved for patients who frequently relapse despite adequate doses of aminosalicylates, or are intolerant of 5-ASA therapy (grade C). It is common practice to continue aminosalicylates with azathioprine, but limited evidence that this is necessary.

- Patients with gastrointestinal intolerance of azathioprine may be cautiously tried on mercaptopurine before being considered for other therapy or surgery (grade $B$ ).

\section{Recommendation}

5.4.1 Patients with ulcerative colitis should normally receive maintenance therapy with aminosalicylates, azathioprine, or mercaptopurine to reduce the risk of relapse.

\subsection{MEDICAL MANAGEMENT OF CROHN'S DISEASE}

The severity of CD is more difficult to assess than UC. The general principles are to consider the site (ileal, ileocolic, colonic, other), pattern (inflammatory, stricturing, fistulating) and activity of the disease before treatment decisions are made in conjunction with the patient.

An alternative explanation for symptoms other than active disease should be considered (such as bacterial overgrowth, bile salt malabsorption, fibrotic strictures, dysmotility, gall 
stones) and disease activity confirmed (usually by CRP or ESR) before starting steroids. Individuals with CD have many investigations over their lifetime and imaging (colonoscopy, small bowel radiology) should not be repeated unless it will alter management or a surgical decision depends on the result.

\subsection{Active ileal/ileocolonic/colonic disease ${ }^{25}$ 29-31 40-445758 69-71 91-93}

Patients should be encouraged to participate actively in the decision to treat with high dose aminosalicylates, different corticosteroids, nutritional therapy, antibiotics, new biological agents, or surgery. Infliximab is considered in section 6.5.

- In mild ileocolonic $\mathrm{CD}$, high dose mesalazine (4 g/daily) may be sufficient initial therapy (grade $A$ ).

- For patients with moderate to severe disease, or those with mild to moderate ileocolonic CD that has failed to respond to oral mesalazine, oral corticosteroids such as prednisolone $40 \mathrm{mg}$ daily is appropriate (grade A).

- Prednisolone should be reduced gradually according to severity and patient response, generally over 8 weeks. More rapid reduction is associated with early relapse (grade C).

- Budesonide $9 \mathrm{mg}$ daily is appropriate for patients with isolated ileo-caecal disease with moderate disease activity, but marginally less effective than prednisolone (grade A).

- Intravenous steroids (hydrocortisone $400 \mathrm{mg} / \mathrm{day}$ or methylprednisolone $60 \mathrm{mg} /$ day) are appropriate for patients with severe disease (grade B). Concomitant intravenous metronidazole is often advisable, because it may be difficult to distinguish between active disease and a septic complication.

- Elemental or polymeric diets are less effective than corticosteroids, but may be used to induce remission in selected patients with active CD who have a contraindication to corticosteroid therapy, or who would themselves prefer to avoid such therapy (grade A).

- Elemental or polymeric diets are appropriate adjunctive therapy (grade $C$ ).

- Total parenteral nutrition is appropriate adjunctive therapy in complex, fistulating disease (grade B).

- Sulphasalazine $4 \mathrm{~g}$ daily is effective for active colonic disease, but cannot be recommended as first line therapy in view of a high incidence of side effects. It may be appropriate in selected patients (grade $A$ ).

- Metronidazole $10-20 \mathrm{mg} / \mathrm{kg} /$ day, although effective, is not usually recommended as first line therapy for CD in view of the potential for side effects (grade A). It has a role in selected patients with colonic or treatment resistant disease, or those who wish to avoid steroids.

- Topical mesalazine may be effective in left sided colonic CD of mild to moderate activity (grade $B$ ).

- Azathioprine $1.5-2.5 \mathrm{mg} / \mathrm{kg} /$ day or mercaptopurine $0.75-1.5 \mathrm{mg} / \mathrm{kg} /$ day may be used in active CD as adjunctive therapy and as a steroid sparing agent. However, its slow onset of action precludes its use as a sole therapy (grade A).

- Infliximab $5 \mathrm{mg} / \mathrm{kg}$ is effective (grade $A$ ), but is best avoided in patients with obstructive symptoms (see section 6.5).

- Surgery should be considered for those who have failed medical therapy and may be appropriate as primary therapy in patients with limited ileal or ileo-caecal disease (grade C).

\section{Recommendations}

6.1.1 Initial treatment of active ileal or ileocolonic Crohn's disease with high dose mesalazine, corticosteroids, nutritional therapy, or surgery should be tailored to the severity of disease and take the views of the patient into account.

6.1.2 There is insufficient evidence to recommend the use of other agents outside trials or specialist centres.

\subsection{Fistulating and perianal disease $e^{72739596}$}

Active perianal disease or fistulae are often associated with active CD elsewhere in the gastrointestinal tract. The initial aim should be to treat active disease and sepsis. For more complex, fistulating disease, the approach involves defining the anatomy, supporting nutrition, and potential surgery. For perianal disease, MRI and examination under anaesthetic are particularly helpful.

- Metronidazole $400 \mathrm{mg}$ tds (grade A) and/or ciprofloxacin $500 \mathrm{mg}$ bd (grade B) are appropriate first line treatments for simple perianal fistulae.

- Azathioprine $1.5-2.5 \mathrm{mg} / \mathrm{kg} /$ day or mercaptopurine $0.75-1.5 \mathrm{mg} / \mathrm{kg} /$ day are potentially effective for simple perianal fistulae or enterocutaneous fistulae where distal obstruction and abscess have been excluded (grade A).

- Infliximab (three infusions of $5 \mathrm{mg} / \mathrm{kg}$ at 0,2 , and 6 weeks) should be reserved for patients whose perianal or enterocutaneous fistulae are refractory to other treatment and should be used as part of a strategy that includes immunomodulation and surgery (grade A).

- Surgery (section 7), including Seton drainage, fistulectomy, and the use of advancement flaps is appropriate for persistent or complex fistulae in combination with medical treatment (grade C).

- Elemental diets or parenteral nutrition have a role as adjunctive therapy, but not as sole therapy (grade B).

- There is insufficient evidence to recommend other agents outside clinical trials or specialist centres.

\section{Recommendation}

6.2.1 Controlled therapeutic trials combining medical and surgical therapy in perianal Crohn's disease should be conducted.

\subsection{Other sites ${ }^{97-99}$}

The same general principles apply, although there are no randomised controlled trials in the treatment of gastroduodenal or diffuse small bowel disease.

- Oral Crohn's disease. This is best managed in conjunction with a specialist in oral medicine. Topical steroids, topical tacrolimus, intra-lesional steroid injections, enteral nutrition, and infliximab may have a role in management but there are no randomised controlled trials.

- Gastroduodenal disease. Symptoms are often relieved by proton pump inhibitors. Surgery is difficult and may be complicated by fistulation.

- Diffuse small bowel disease. Stricture dilatation or strictureplasty with or without triamcinolone injection should be considered. Nutritional support before and after surgery is 
usually essential. Other approaches, including the combination of infliximab with surgery for residual strictures, are evolving.

6.4 Maintenance of remission' 25273136404546525971 100-103 The efficacy of drug therapy appears to depend on whether remission was achieved with medical or surgical therapy, on the risk of relapse, and site of disease. Smoking cessation is probably the most important factor in maintaining remission.

To reduce the risk of relapse in $\mathrm{CD}$ :

- All smokers should be strongly advised to stop (grade A), with help (counselling, nicotine patches, or substitutes) offered to achieve this

- Mesalazine has limited benefit and is ineffective at doses $<2 \mathrm{~g} /$ day, or for those who have needed steroids to induce remission (grade $A$ ).

- Azathioprine $1.5-2.5 \mathrm{mg} / \mathrm{kg} / \mathrm{day}$ or mercaptopurine $0.75-1.5 \mathrm{mg} / \mathrm{kg}$ are effective, but reserved as second line therapy because of potential toxicity (grade $A$ ).

- Methotrexate (15-25 mg IM weekly) is effective for patients whose active disease has responded to IM methotrexate (grade $A$ ). It is appropriate for those intolerant of, or who have failed, azathioprine/mercaptopurine therapy (grade B) once potential toxicity and other options, including surgery, have been discussed with the patient. Folic acid $5 \mathrm{mg}$ once a week, taken 3 days after methotrexate, may reduce side effects. Subcutaneous or oral therapy may be effective (grade B).

- Infliximab is effective at a dose of $5-10 \mathrm{mg} / \mathrm{kg}$ every 8 weeks in patients who have responded to an initial infusion 12 weeks earlier, for up to 44 weeks (grade $A$ ). It is best used as part of treatment strategy including immunomodulation once other options, including surgery, have been discussed with the patient (grade B).

- Sulphasalazine cannot be recommended (grade A).

- Corticosteroids, including budesonide, are not effective (grade A), although some patients have chronic active disease who appear steroid dependent (below).

Recommendations

6.4.1 Patients with Crohn's disease who smoke should be offered help to stop.

6.4.2 Immunomodulation with azathioprine, mercaptopurine, or methotrexate is usually appropriate if patients relapse more than once per year as steroids are withdrawn.

\subsection{Chronic active and steroid dependent \\ disease 4559697191103}

Long term treatment with steroids is undesirable. Patients who have a poor response to steroids can be divided into steroid refractory and steroid dependent. Steroid-refractory disease may be defined as active disease in spite of an adequate dose and duration of prednisolone $(\geqslant 20 \mathrm{mg} / \mathrm{d}$ for $\geqslant 2$ weeks) and steroid dependence as a relapse when the steroid dose is reduced below $20 \mathrm{mg} /$ day, or within 6 weeks of stopping steroids. Such patients should be considered for treatment with immunomodulators if surgery is not an immediate consideration.

- Azathioprine 1.5-2.5 mg/kg/day, or mercaptopurine 0.75$1.25 \mathrm{mg} / \mathrm{kg} /$ day are the first line agents of choice for steroid dependent disease (grade $A$ ).
- Monitoring the FBC to detect neutropenia is advisable, although there is no evidence that this is effective because profound neutropenia and sepsis can develop rapidly. The FBC is best checked within 4 weeks of starting therapy and every 6-12 weeks thereafter, although may be done more frequently. Routine measurement of thiopurine methyltransferase activity before treatment, which may identify some (but not all) patients at risk of neutropenia, cannot yet be recommended but is debated. Large published series report safe use of azathioprine without TPMT assay.

- Methotrexate IM $25 \mathrm{mg}$ weekly for up to 16 weeks followed by $15 \mathrm{mg}$ weekly is effective for chronic active disease (grade $A$ ). Oral dosing is effective for many patients (grade B).

- Infliximab (5 mg/kg) should be reserved for patients with moderate to severe $\mathrm{CD}$, who are refractory to or intolerant of treatment with steroids, mesalazine, azathioprine/ mercaptopurine, and methotrexate, and where surgery is considered inappropriate (grade A).

\section{Recommendation}

6.5.1 Immunomodulation with azathioprine, mercaptopurine, or methotrexate should be tried if steroids cannot be withdrawn without deterioration in disease activity.

\subsection{SURGERY FOR INFLAMMATORY BOWEL DISEASE}

\subsection{General principles ${ }^{114-119}$}

For UC, surgery should be advised for disease not responding to intensive medical therapy. The decision to operate is best taken by the gastroenterologist and colorectal surgeon in conjunction with the patient. Other patients with dysplasia or carcinoma, poorly controlled disease, recurrent acute on chronic episodes of UC, or those with a retained rectal stump following previous colectomy should be counselled regarding surgical options.

For CD, surgery should only be undertaken for symptomatic rather than asymptomatic, radiologically identified disease, because it is potentially panenteric and usually recurs following surgery. Resections should be conservative.

There are few randomised controlled trials of surgical options and practice in IBD. General principles are as follows:

- Patients requiring surgery for IBD are best managed under the joint care of a surgeon and a gastroenterologist with an interest in IBD (grade C).

- Preoperative counselling and marking of stoma sites should be performed by a clinical colorectal nurse specialist in stoma therapy (grade $C$ ).

- Midline incisions should usually be employed for IBD patients requiring laparotomy (grade B).

- The procedure of choice in acute fulminant UC or CD is a subtotal colectomy leaving a long rectal stump, either incorporated into the lower end of the abdominal wound or exteriorised as a mucus fistula, to facilitate later rectal excision and minimise the risk of intraperitoneal dehiscence (grade B).

- Patients requiring elective surgery for UC should be counselled regarding all surgical options, including ileoanal pouch where appropriate (grade $C$ ).

- Resections in CD should be limited to macroscopic disease (grade $A$ ).

- Primary anastomosis should not be performed in the presence of sepsis and malnutrition (grade B). 
- Anal and perianal CD should be treated surgically only when symptomatic (grade B).

- Procedures for perianal CD should usually be conservative and in conjunction with medical treatment, particularly aiming at drainage of sepsis. Repair of fistulas may be appropriate in selected cases with absent or minimal rectal disease (grade B).

\subsection{Preventing postoperative recurrence $\begin{array}{llll}25 & 26 & 120-127\end{array}$} For patients who smoke, cessation significantly reduces postoperative relapse. Additional medical therapy should be considered for at least 18 months after surgery, especially if disease has frequently relapsed prior to surgery, or after surgery for fistulating disease, or after a second operation.

- All smokers should be strongly advised to stop (grade B), with help offered to achieve this.

- Mesalazine ( $\geqslant 2 \mathrm{~g} /$ day) lowers postoperative recurrence in small bowel disease (grade $A$ ), but is ineffective after colonic resection.

- Azathioprine $1.5-2.5 \mathrm{mg} / \mathrm{kg} /$ day or mercaptopurine $0.75-1.5 \mathrm{mg} / \mathrm{kg} / \mathrm{day}$ may be used for preventing postoperative recurrence and may be better than mesalazine (grade B).

- Metronidazole (20 mg/kg/day for 3 months) effectively delays recurrence after ileocolic resection for up to 18 months (grade $A$ ), but potential side effects include peripheral neuropathy.

\subsection{Pouchitis ${ }^{128-132}$}

\section{Recommendations}

7.2.1 Patients who smoke should be strongly advised to stop and offered help to achieve this.

7.2.2 Postoperative adjuvant treatment should be considered in all patients and normally be used for patients who have frequently relapsed before surgery.

Up to $45 \%$ of patients who undergo ileal pouch surgery for UC suffer from pouchitis. Pouchitis is a new disease and diagnostic criteria have only recently been proposed. Conditions that mimic pouchitis (cuffitis, pelvic sepsis, prepouch ileitis, irritable pouch) should be considered. There are few trials of treatment:

- Metronidazole $400 \mathrm{mg}$ tds (grade A) or ciprofloxacin $250 \mathrm{mg}$ bd (grade B) for 2 weeks is the first line therapy of choice for pouchitis.

- Mesalazine or corticosteroids may be used in acute pouchitis if antibiotics are ineffective (grade C).

- Long term, low dose metronidazole or ciprofloxacin are potentially effective for chronic pouchitis (grade B).

- VSL3 probiotic therapy (although not widely available) may be used for chronic pouchitis (grade A).

\section{Recommendations}

7.3.1 The diagnosis of pouchitis should normally be made on clinical and endoscopic and histological criteria.

7.3.2 Initial therapy with metronidazole or ciprofloxacin is appropriate, which may need to be continued for extended periods in the minority of patients who frequently relapse.

\subsection{ASSOCIATED ASPECTS OF INFLAMMATORY BOWEL DISEASE \\ 8.1 Pain management}

Abdominal pain is a common but under-researched feature of IBD. There are many potential mechanisms. These include acute and subacute obstruction in CD due to disease or adhesions, serosal and mucosal inflammation, visceral hypersensitivity, secondary irritable bowel syndrome, proctalgia fugax, the likely impact of emotional factors on pain thresholds, and visceral distension where there is dilation. Gall stones, renal calculi, and chronic pancreatitis should be considered. In addition, arthritis, iritis, and painful skin complications require analgesia in many patients. Most analgesics are relatively ineffective and have the potential to worsen underlying disease. Where possible, treatment is of the underlying cause (including corticosteroids and if appropriate, treatment of associated irritable bowel syndrome). Where non-specific pain relief is needed, an opioid that has less effect on motility such as tramadol may help.

\subsection{Surveillance for colonic carcinoma ${ }^{24}$ 133-136}

The value of surveillance colonoscopy in UC remains debated. It is important to discuss with individual patients their risk of colorectal cancer, the implications should dysplasia be identified, the limitations of surveillance (which may miss dysplasia), and the small, but definable, risks of colonoscopy. A joint decision on the appropriateness of surveillance can then be made, taking the patient's views into account.

- It is advisable that patients with UC should have a colonoscopy after 8-10 years to re-evaluate disease extent (grade $C$ ). Whether patients with previously extensive disease whose disease has regressed benefit from surveillance is unknown.

- For those with extensive colitis opting for surveillance, colonoscopies should be conducted every 3 years in the second decade, every 2 years in the third decade, and annually in the fourth decade of disease (grade C).

- Four random biopsies every $10 \mathrm{~cm}$ from the entire colon are best taken with additional samples of suspicious areas (grade C).

- Patients with primary sclerosing cholangitis appear to represent a subgroup at higher risk of cancer, and they should have more frequent (perhaps annual) colonoscopy (grade C).

- If dysplasia (of any grade) is detected, the biopsies should be reviewed by a second gastrointestinal pathologist and if confirmed, then colectomy is usually advisable (grade C).

\section{Recommendation}

8.2.1 The appropriateness of surveillance should be discussed with patients who have ulcerative colitis or Crohn's colitis and a joint decision made on the balance of benefit to the individual.

\subsection{Management of pregnancy ${ }^{53} 138139$}

As both UC and CD often occur in young adults, managing IBD in pregnancy is not uncommon. It has been estimated that approximately $25 \%$ of female patients conceive after the diagnosis of IBD has been made. Maintaining adequate disease control during pregnancy is essential for both maternal and fetal health. 
- If planning pregnancy, patients should be counselled to conceive during remission and advised to continue their maintenance medication. Before conception, patients should be well nourished and take folate supplements.

- Flexible sigmoidoscopy may be used safely where the information provided will significantly alter management. The least extensive procedure possible should be employed (grade B).

- Patients with acute severe colitis or other life threatening complications of disease should be managed as for the non-pregnant patient, including abdominal radiograph. The best interests of the fetus are served by optimal management of maternal IBD (grade B).

- The mode of delivery should be carefully considered. It may be best for patients with perianal CD or ileoanal pouch formation to have a Caesarian section to avoid the risk of damage to the anal sphincter.

- Sulphasalazine should be stopped if there is suspected neonatal haemolysis (grade B).

- Azathioprine should in general be continued during pregnancy, as the risks to the fetus from disease activity appear to be greater than continued therapy. Babies born to mothers on azathioprine may be lighter than normal and the risk-benefit ratio should be discussed with patients (grade B).

- Corticosteroids can be used for active disease, as the risks to the pregnancy from disease activity are greater than from continued therapy (grade B).

- Methotrexate is absolutely contraindicated in pregnancy (grade B).

- Absolute indications for surgery are unaltered by pregnancy and surgery should only be delayed where aggressive medical therapy may allow critical fetal maturation (grade $C$ ).

- Intestinal resection should be covered by a defunctioning stoma. Primary anastomosis is best avoided (grade B).

\subsection{Nutrition 9293 140-145}

There is little evidence to implicate dietary components in the aetiology or pathogenesis of UC. However, patients are prone to malnutrition and its detrimental effects. There is no evidence that artificial nutritional support alters the inflammatory response in $\mathrm{UC}$, in contrast to $\mathrm{CD}$.

For $C D$, nutrition should be considered an integral component of the management of all patients. Malnutrition is common and multifactorial in origin. Nutritional status (including body mass index) is best assessed at diagnosis and periodically thereafter. As a minimum, patients should be weighed on outpatient attendance or in primary care. In children and adolescents, regular monitoring with height and weight centile charts are mandatory. Specific attention should be paid to vitamin B12 status, especially after ileal resection.

- Nutritional support is appropriate as disease modifying therapy for growth failure in children or adolescents with active small bowel disease (grade A). After detailed discussion it may be used in preference to steroids, immunomodulators, or surgery for any patient with active disease (grade B), or for those unresponsive to mesalazine or in whom corticosteroids are contraindicated (grade C).

- Nutritional support is appropriate as adjunctive therapy for any malnourished patients (grade $C$ ), or for those who have difficulty maintaining normal nutritional status (grade $C$ ).
- Nutritional support is appropriate for those with intestinal partial obstruction awaiting surgery (grade $C$ ), or severely symptomatic perianal disease (grade $C$ ), or those with postoperative complications. Enteral nutrition is preferred when the patient's condition permits (grade C).

- Serum vitamin B12 is best measured annually in patients with ileal CD (grade C).

\subsection{Management of extraintestinal manifestations ${ }^{146}$}

Extraintestinal manifestations are found in both CD and UC. Those that are associated with active intestinal disease largely respond to therapy aimed at controlling disease activity, whereas those that occur whether disease is inactive or quiescent run a course independent of therapy for intestinal disease. Extraintestinal manifestations are more common in Crohn's colitis and ileocolitis than in exclusively small bowel disease.

\subsection{Osteoporosis ${ }^{147-151}$}

Osteoporosis is common in patients with IBD (see BSG Guidelines for osteoporosis in coeliac disease and inflammatory bowel disease), although the absolute fracture risk, contribution of steroids and role of prophylaxis remain a subject for debate.

\subsection{The role of the IBD nurse specialist ${ }^{151}$}

The IBD clinical nurse specialist represents a new role for the management of patients with IBD. Nurse specialists are widely appreciated by patients, relatives, and medical staff. Evolving evidence confirms their cost effectiveness (grade $C$ ). The role of the IBD specialist nurse needs defining, but may encompass:

- liaising with all members of the MDT, patients, primary care, and other agencies;

- support of patients and carers both in hospital and the community in all aspects of care of IBD;

- establishment of nurse-led services, including clinics, telephone helplines, and follow up, rapid access for patients, and referral to other professionals;

- development of systems to enable audit and participation in research projects promoting the care of IBD patients;

- developing and leading teaching plans for patients and other healthcare professionals involved in IBD management.

\subsection{Sources of patient information}

Many sources of information are available to complement explanations or advice given by clinical staff. Patients usually welcome further information, but it should be appropriate and relevant to their condition. In general, patients should be offered advice on where additional information may be obtained and help in interpreting information where the need arises. Sources are too many to provide a comprehensive list. The following provide access to both general and more detailed information:

- NACC: The National Association for Colitis and Crohn's disease, 4 Beaumont House, Sutton Road, St Albans, Herts ALl 5HH, UK. Information Line: 01727 844296; website: Www.nacc.org.uk

- CCFA: The Crohn's and Colitis Foundation of America; website: www.ccfa.org

- CORE/DDF: Digestive Diseases Foundation, PO Box 251, Edgware, Middlesex, HA8 6HG, UK. 


\subsection{CONTRIBUTING AUTHORS}

Dr N Breslin, Mr R Driscoll, Dr A Forbes, Mr P Goodfellow, Dr $S$ Halligan, Professor CJ Hawkey, Dr AB Hawthorne, Professor C O'Morain, Dr CSJ Probert, Dr DS Rampton, Ms J Sercombe, Dr J Shaffer, Mr AJ Shorthouse, Dr BF Warren, Ms S Wood.

\section{Authors' affiliations}

M J Carter, Division of Molecular and Genetic Medicine, Royal Hallamshire Hospital, Sheffield, UK

A J Lobo, Gastroenterology and Liver Unit, Royal Hallamshire Hospital, Sheffield, UK

S P L Travis, Gastroenterology Unit, John Raddliffe Hospital NHS Trust, Oxford, UK

Correspondence to: Dr S Travis, Gastroenterology Unit, John Radcliffe Hospital NHS Trust, Oxford OX3 9DU, UK; simon.travis@orh.nhs.uk

\subsection{REFERENCES}

1 Eccles M, Clapp Z, Grimshaw J, et al. North of England evidence based guidelines development project methods of guideline development. BMJ 1996:312:760-2.

2 Loftus EV Jr. Clinical epidemiology of inflammatory bowel disease: incidence, prevalence, and environmental influences. Gastroenterology 2004; 126:1504-17.

3 Longobardi T, Jacobs T, Wu L, et al. Work losses related to inflammatory bowel disease in Canada: results from a national population health survey. Am J Gastroenterol 2003;98:844-9.

4 Card T, Hubbard R, Logan RFA. Mortality in inflammatory bowel disease: a population-based cohort study. Gastroenterology 2003;125:1583-90.

5 Robinson A, Thompson DG, Wilkin D, et al. Guided self-management and practice-directed follow-up of ulcerative colitis: a randomised trial. Lancet 2001;358:976-81

6 Shivananda S, Lennard-Jones JE, Logan $R$, et al. Incidence of inflammatory bowel disease across Europe: is there a difference between north and south? Results of the European collaborative study on inflammatory bowel disease (EC-IBD). Gut 1996;39:690-7.

7 Sands BE. From symptom to diagnosis: clinical distinctions among various forms of intestinal inflammation. Gastroenterology 2004;126:1518-32.

8 Gasche C, Scholmerich J, Brynskov J, et al. A simple classification of Crohn's disease: report of the Working Party for the World Congress of Gastroenterology, Vienna 1998. Inflamm Bowel Dis 2000;6:8-15.

9 Lapidus A, Bernell O, Hellers G, et al. Incidence of Crohn's disease in Stockholm county 1955-1989. Gut 1997;41:480-6

10 Rubin GP, Hungin AP, Kelly PJ, et al. Inflammatory bowel disease: epidemiology and management in an English general practice population. Aliment Pharmacol Ther 2000;14:1553-9.

11 Ardizzone S, Porro GB. Inflammatory bowel disease: new insights into pathogenesis and treatment. J Intern Med 2002;252:475-96.

12 Munkholm P, Langholz E, Davidsen $M$, et al. Disease activity courses in a regional cohort of Crohn's disease patients. Scand J Gastroenterol 1995; 30:699-706.

13 Langholz E, Munkholm P, Davidsen M, et al. Course of ulcerative colitis: analysis of changes in disease activity over years. Gastroenterology 1994;107:3-11.

14 Munkholm P, Langholz E, Davidsen $M$, et al. Intestinal cancer risk and mortality in patients with Crohn's disease. Gastroenterology 1993; 105:1716-23.

15 Lennard-Jones JE, Shivananda S and the EC-IBD Study Group. Clinical uniformity of inflammatory bowel disease at presentation and during the first year of disease in the north and south of Europe. Eur J Gastroenterol \& Hepatol 1997;9:353-9.

16 Winther K, Jess T, Langholz E, et al. Survival and cause-specific mortality in ulcerative colitis: follow-up of a population-based cohort in Copenhagen County. Gastroenterology 2003;125:1576-82.

17 Sandborn WJ, Feagan BG, Hanauer SB, et al. Review of activity indices and efficacy endpoints for clinical trials of medical therapy in adults with Crohn's disease. Gastroenterology 2002; 122:512-30.

18 Truelove SC, Witts $\sqcup$. Cortisone in ulcerative colitis: final report on a therapeutic trial. BMJ 1955;ii:1041-8.

19 Walmsley RS, Ayres RCS, Pounder RE, et al. A simple clinical colitis index. Gut 1998;43:29-32.

20 Jenkins D, Balsitis M, Gallivan S, et al. Guidelines for the initial biopsy diagnosis of suspected chronic idiopathic inflammatory bowel disease. The British Society of Gastroenterology Initiative. J Clin Path 1997;50:93-105.

21 Scotiniotis I, Rubesin SE, Ginsberg G. Imaging modalities in inflammatory bowel disease. Gastroenterol Clin N Am 1999;28:391-421.

22 Sandborn WJ, Hanauer SB. Systematic review: the pharmacokinetic profiles of oral mesalazine formulations and mesalazine prodrugs used in the management of ulcerative colitis. Aliment Pharmacol Ther 2003;17:29-42.

23 Sutherland LR, Roth D, Beck P, et al. Oral 5-aminosalicylic acid for maintaining remission in ulcerative colitis. Cochrane Database Syst Rev 2002;(4):CD000544.

24 Eaden J, Abrams K, Ekbom A, et al. Colorectal cancer prevention in ulcerative colitis: a case-control study. Aliment Pharmacol Ther 2000; 14:145-53.
25 Hanauer SB, Strömberg U. Oral Pentasa in the treatment of active Crohn's disease: a meta-analysis of double-blind, placebo-controlled trials. Clin Gastroenterol Hepatol 2004;2:379-88.

26 Lochs H, Mayer M, Fleig WE, et al. Prophylaxis of post-operative relapse in Crohn's disease with mesalamine: European Cooperative Crohn's Disease Study Vl. Gastroenterology 2000;1 18:264-273.

27 Modigliani R, Colombel JF, Dupas JL, et al. Mesalamine in Crohn's disease with steroid-induced remission: effect on steroid withdrawal and remission maintenance. Gastroenterology 1996;108:688-93.

28 Sutherland L, Roth D, Beck, et al. Oral 5-aminosalicylic acid for inducing remission in ulcerative colitis. Cochrane Database Syst Rev 2000;(2):CD000543

29 Feagan BG. 5-ASA therapy for active Crohn's disease: old friends, old data and a new conclusion. Clin Gastroenterol Hepatol 2004;2:376-8.

30 Prantera C, Cottone M, Pallone F, et al. Mesalamine in the treatment of mild to moderate active Crohn's ileitis: results of a randomized multicenter trial. Gastroenterology 1999;116:521-6.

31 Summers RW, Switz DM, Sessions JT, et al. National co-operative Crohn's disease study group: results of drug treatment. Gastroenterology 1979:77:847-69.

32 Loftus EV, Kane SV, Bjorkman D. Systemic review: short-term adverse effects of 5 -aminosalicylic acid agents in the treatment of ulcerative colitis. Aliment Pharmacol Ther 2004;19:179-89.

33 Ransford RAJ, Langman MJS. Sulphasalazine and mesalazine: serious adverse reactions re-evaluated on the basis of suspected adverse reaction reports to the Committee on Safety of Medicines. Gut 2002;51:536-39.

34 van Staa TP, Travis SPL, Leufkens HJM, et al. 5-aminosalicylic acids and the risk of renal disease: a large British epidemiological study. Gastroenterology 2004; 126:1733-9.

35 Franchimont D, Kino T, Galon J, et al. Glucorticoids and inflammation revisited: the state of the art. Neuroimmunomodulation 2003;10:247-60.

36 Steinhart AH, Ewe K, Griffiths AM, et al. Corticosteroids for maintaining remission of Crohn's disease. Cochrane Database Syst Rev $2001 ;(3)$ :CD000301.

37 Truelove SC, Watkinson G, Draper G. Comparison of corticosteroid and SASP therapy in ulcerative colitis. BMJ 1962;2:1708-11.

38 Lennard-Jones JE, Longmore AJ, Newell AC, et al. An assessment of prednisone, Salazopyrin and topical hydrocortisone hemisuccinate used as outpatient treatment for ulcerative colitis. Gut 1960;1:217-22.

39 Baron JH, Connell AM, Kanaghinis TG, et al. Outpatient treatment of ulcerative colitis: comparison between three doses of oral prednisone. BMJ 1962;2:441-3.

40 Malchow H, Ewe K, Brandes JW, et al. European co-operative Crohn's disease study (ECCDS): results of drug treatment. Gastroenterology 1984;86:249-66.

41 Modigliani R, Mary JY, Simon JF, et al. Clinical, biological and endoscopic picture of attacks of Crohn's disease. Evolution on prednisolone. Groupe d'Etude Therapeutique des Affections Inflammatoires Digestives. Gastroenterology 1990;98:811-18.

42 Kane SV, Schoenfeld P, Sandborn W, et al. Systematic review: the effectiveness of budesonide for Crohn's disease. Aliment Pharmacol Ther 2002; 16:1509-17.

43 Tiede I, Fritz G, Strand S, et al. CD28-dependent Racl activation is the molecular target of aziothioprine in primary human CD4+ T lymphocytes. J Clin Invest 2003;111:1133-45.

44 Sandborn W, Sutherland L, Pearson D, et al. Azathioprine or 6mercaptopurine for inducing remission of Crohn's disease. Cochrane Database Syst Rev 2000;(2):CD000545.

45 Pearson DC, May GR, Fick GR, et al. Azathioprine for maintaining remission of Crohn's disease. Cochrane Database Syst Rev 2000;(2):CD000067.

46 Lemann M, Bouhnik Y, Colombel J, et al. Randomized, double-blind placebo-controlled, multicentre, azathioprine withdrawal trial in Crohn's disease. Gastroenterology 2002;122:A23.

47 Jewell DP, Truelove SC. Azathioprine in ulcerative colitis: final report on a controlled therapeutic trial. BMJ 1974;ii:627-30.

48 McGovern DPB, Travis SPL. Thiopurine therapy: when to start and when to stop. Eur J Gastroenterol Hepatol 2003;15:219-24.

49 Hawthorne AB, Logan RFA, Hawkey CJ, et al. Randomised controlled trial of azathioprine-withdrawal in ulcerative colitis. BMJ 1992;305:20-22.

50 Lennard L, Gibson BE, Nicole T, et al. Congenital thiopurine methyltransferase deficiency and 6-mercaptopurine toxicity during treatment for acute lymphoblastic leukaemia. Arch Dis Child 1993;69:577-9.

51 Colombel JF, Ferrari N, Debuysere H, et al. Genotypic analysis of thiopurine S-methyltransferase in patients with Crohn's disease and severe myelosuppression during azathioprine therapy. Gastroenterology 2000; 118:1025-30.

52 Fraser AG, Orchard TR, Jewell DP. The efficacy of azathioprine for the treatment of inflammatory bowel disease: a 30 year review. Gut 2002:50:485-9.

53 Francella A, Dyan A, Bodian C, et al. The safety of 6-mercaptopurine for child-bearing patients with inflammatory bowel disease: a retrospective cohort study. Gastroenterology 2003;124:9-17.

54 Connell WR, Kamm MA, Ritchie JK, et al. Bone marrow toxicity caused by azathioprine in inflammatory bowel disease: 27 years of experience. Gut 1993;34:1081-5.

55 Lewis JD, Bilker WB, Brensinger C, et al. Inflammatory bowel disease is not associated with an increased risk of lymphoma. Gastroenterology 2001;121:1080-7.

56 Lewis JD, Schwartz JS, Lichtenstein GR. Azathioprine for maintenance of remission in Crohn's disease: benefits outweigh the risk of lymphoma. Gastroenterology 2000;118:1018-24 
57 Fraser AG. Methotrexate: first or second-line immunomodulator? Eur J Gastroenterol Hepatol 2003;15:225-31.

58 Alfadhli AA, McDonald JW, Feagan BG. Methotrexate for induction of remission in refractory Crohn's disease (Cochrane Review). Cochrane Database Syst Rev 2003;(1):CD003459.

59 Feagan BG, Fedorak RN, Irvine EJ, et al. A comparison of methotrexate with placebo for the maintenance of remission in Crohn's disease. North American Crohn's Study Group Investigators. N Engl J Med 2000;342:1627-32.

60 Hamilton RA, Kremer JM. Why intramuscular dosing may be more efficacious than oral dosing in patients with rheumatoid arthritis. Br J Rheumatol 1997;36:86-90.

61 Te HS, Schiano TD, Kuan SF, et al. Hepatic effects of long-term methotrexate use in the treatment of inflammatory bowel disease. Am J Gastroenterol 2000;95:3150-6.

62 Hawthorne AB. Ciclosporin and refractory colitis. Eur J Gastroenterol Hepatol 2003; 15:239-44.

63 Lichtiger S, Present DH, Kornbluth A, et al. Cyclosporine in severe ulcerative colitis refractory to steroid therapy. N Engl J Med 1994;330:1841-5.

64 D'Haens G, Lemmens L, Geboes K, et al. Intravenous cyclosporine versus intravenous corticosteroids as single therapy for severe attacks of ulcerative colitis. Gastroenterology 2001;120:1323-9.

65 Van Assche G, D'Haens G, Noman M, et al. Randomized, double-blind comparison of $4 \mathrm{mg} / \mathrm{kg}$ versus $2 \mathrm{mg} / \mathrm{kg}$ intravenous cyclosporine in severe ulcerative colitis. Gastroenterology 2003;125:1025-31.

66 Actis GC, Aimo G, Priolo G, et al. Efficacy and efficiency of oral microemulsion ciclosporin versus intravenous and soft gelatin capsule ciclosporin in the treatment of severe steroid-refractory ulcerative colitis: an open-label retrospective trial. Inflamm Bowel Dis 1998;4:276-9.

67 Actis GC, Bresso F, Astegiano M, et al. Safety and efficacy of azathioprine in the maintenance of ciclosporin-induced remission of ulcerative colitis. Aliment Pharmacol Ther 2001;15:131-7.

68 Feagan BG. Cyclosporin has no proven role as a therapy for Crohn's disease. Inflamm Bowel Dis 1995;1:335-9.

69 Rutgeerts P, Van Assche G, Vermeire S. Optimising anti-TNF treatment in inflammatory bowel disease. Gastroenterology 2004;126:1593-610.

70 Targan SR, Hanaver SB, van Deventer SJ, et al. A short-term study of chimeric monoclonal antibody CA2 to tumor necrosis factor alpha for Crohn's disease. Crohn's Disease cA2 Study Group. N Engl J Med 1997;337:1029-35

71 Hanaver SB, Feagan BG, Lichtenstein GR, et al. Maintenance infliximab for Crohn's disease: the ACCENT 1 randomised trial. Lancet 2002;359:1541-9.

72 Present DH, Rutgeerts P, Targan S, et al. Infliximab for the treatment of fistulas in patients with Crohn's disease. N Engl J Med 1999;340:1398-405.

73 Sands BE, Anderson FH, Bernstein CN, et al. Infliximab maintenance therapy for fistulizing Crohn's disease. N Engl J Med 2004;350:876-85.

74 Ljung T, Karlen P, Schmidt D, et al. Infliximab in inflammatory bowel disease: clinical outcome in a population based cohort from Stockholm County. Gut 2004; 53:849-53.

75 Colombel JF, Loftus EV Jr, Tremaine WJ, et al. The safety profile of infliximab in patients with Crohn's disease: the Mayo clinic experience in 500 patients. Gastroenterology 2004;126:19-31.

76 Margolin ML, Krumholz MP, Fochios SE, et al. Clinical trials in ulcerative colitis: II. Historical review. Am J Gastroenterol 1988;83:227-43.

77 Cohen RD, Woseth DM, Thisted RA, et al. A meta-analysis and overview of the literature on treatment options for left-sided ulcerative colitis and ulcerative proctitis. Am J Gastroenterol 2000;95:1263-76.

78 Marshal JK, Irvine EJ. Rectal corticosteroids versus alternative treatment in ulcerative colitis: a meta-analysis. Gut 1997;40:775-81.

79 Safdi M, DeMicco M, Sninsky C, et al. A double-blind comparison of oral versus rectal mesalamine versus combination therapy in the treatment of ulcerative colitis. Am J Gastro 1997;92:1867-71.

80 Hanauer SB. Dose-ranging study of mesalamine (PENTASA) enemas in the treatment of acute ulcerative proctosigmoiditis: results of a multi-centred placebo-controlled trial. The US PENTASA Enema study group. Inflamm Bowel Dis 1998:4:79-83.

81 Allison MC, Vallance R. Prevalence of proximal faecal stasis in active ulcerative colitis. Gut 1991;32:179-82.

82 Jarnerot G, Rolny P, Sandberg-Gertzen H. Intensive intravenous treatment of ulcerative colitis. Gastroenterology 1985;89:1005-13.

83 Travis SPL, Farrant JM, Ricketts C, et al. Predicting outcome in severe ulcerative colitis. Gut 1996;38:905-10.

84 Hawthorne AB, Travis SPL, and the BSG IBD Clinical Trials Network Outcome of inpatient management of severe ulcerative colitis: a BSG IBD Clinical Trials Network Survey. Gut 2002;50:A16.

85 Chapman RW, Selby WS, Jewell DP. Controlled trial of intravenous metronidazole as an adjunct to corticosteroids in severe ulcerative colitis. Gut 1986;27:1210-12.

86 Daperno M, Sostegni R, Rocca R, et al. Review article: medical treatment of severe ulcerative colitis. Aliment Pharmacol Ther 2002;16:7-12.

87 Dissanayake AS, Truelove SC. A controlled therapeutic trial of long-term maintenance treatment of ulcerative colitis with sulphasalazine. Gut 1973;22:497-500

88 Marteau P, Crand J, Foucault $M$, et al. Use of mesalazine slow-release suppositories $1 \mathrm{~g}$ three times per week to maintain remission of ulcerative proctitis: a randomised double-blind placebo-controlled multicentre study. Gut 1998:42:195-9.

89 Ardizzone S, Molteni P, Bollani S, et al. Guidelines for the treatment of ulcerative colitis in remission. Eur J Gastroenterol \& Hepatol 1997;9:836-41
90 Nielsen $\mathrm{OH}$, Vainer B, Rask-Madsen J. Review article: the treatment of inflammatory bowel disease with 6-mercaptopurine or azathioprine. Aliment Pharmacol Ther 2001;15:1699-708.

91 Caprilli R, Viscido A, Guagnozzi D. Review article: biological agents in the treatment of Crohn's disease. Aliment Pharmacol Ther 2002;16:1579-90.

92 Sutherland LR, Singleton J, Sessions J, et al. Double-blind, placebocontrolled trial of metronidazole in Crohn's disease. Gut 1991;32:1071-5.

93 Ferguson A, Glen M, Ghosh S. Crohn's disease: nutrition and nutritional therapy. Bailleres Clin Gastroenterol 1998;12:93-114.

94 Messori A, Trallori G, D'Albaisio G, et al. Defined-formula diets versus steroids in the treatment of active Crohn's disease: a meta-analysis. Scand J Gastroenterol 1996;31:267-72.

95 Sandborn WJ, Fazio WW, Feagan BG, Hanaver SB, American Gastroenterology Association Clinical practice Committee. AGA technical review on perianal Crohn's disease. Gastroenterology 2003;125:1508-30.

96 Ostro MJ, Greenberg GR, Jeejeebhoy KN. Total parenteral nutrition and complete bowel rest in the management of Crohn's disease. J Parenter Enteral Nutr 1985:9:280-7.

97 Witte AM, Veenendaal RA, Van Hogezand RA, et al. Crohn's disease of the upper gastrointestinal tract: the value of endoscopic examination. Scand J Gastroenterol Suppl 1998;225:100-5.

98 Couckuyt H, Gevers AM, Coremans $G$, et al. Efficacy and safety of hydrostatic balloon dilatation of ileocolonic Crohn's strictures: a prospective long term analysis. Gut 1995;36:577-80.

99 Lavy A. Triamcinolone improves outcome in Crohn's disease strictures. Dis Colon Rectum 1997:40:184-6.

100 Cottone M, Rosselli M, Orlando A, et al. Smoking habits and recurrence in Crohn's disease. Gastroenterology 1994;109:643-8.

101 Camma C, Ciunta M, Rosselli M, et al. Mesalamine in the maintenance treatment of Crohn's disease: a meta-analysis adjusted for confounding variables. Gastroenterology 1997;113:1465-73.

102 Cottone M, Camma C. Mesalamine and relapse prevention in Crohn's disease. Gastroenterology 2000;1 19:597.

103 Travis SPL, ed. Recent advances in immunomodulation in the treatment of inflammatory bowel disease: review in depth. Eur J Gastroenterol Hepatol 2003;15:215-48.

104 Shorthouse AJ. Abdominal surgery for Crohn's disease. Coloproctology 2000;2:55-62.

105 Karch LA, Bauer JJ, Gorfine SR, et al. Subtotal colectomy with Hartmann's pouch for inflammatory bowel disease. Dis Colon Rectum 1995;38:635-9.

106 McKee RF, Keenan RA, Munro A. Colectomy for acute colitis: is it safe to close the rectal stump? Int J Colorect Dis 1995;10:222-4.

$107 \mathrm{Ng}$ RLH, Davies AH, Grace RH, et al. Subcutaneous rectal stump closure after emergency subtotal colectomy. Br J Surg 1992;79:701-3.

108 Hallgren TA, Fasth SB, Oresland TO, et al. Ileal pouch anal function after endoanal mucosectomy and handsewn ileoanal anastomosis compared with stapled anastomosis without mucosectomy. Eur J Surg 1995;161:915-21.

109 Goodfellow PB, Wakefield SE, Anderson JA, et al. Predicting ileoanal pouch function. Coloproctology 2000;2:68-71.

110 Fazio VW, Ziv Y, Church JM, et al. Ileal pouch-anal anastomoses complications and function in 1005 patients. Ann Surg 1995;222:120-7.

111 Reilly WT, Pemberton JH, Wolff BG, et al. Randomised prospective trial comparing ileal pouch-anal anastomosis performed by excising the anal mucosa to ileal pouch-anal anastomosis performed by preserving the ana mucosa. Ann Surg 1997;225:666-7.

112 Leong AP, Londono-Schimmer EE, Phillips RK. Life-table analysis of stomal complications following ileostomy. Br J Surg 1994;81:727-9.

113 Khubchandani IT, Kontostolis SB. Outcome of ileorectal anastomosis in an inflammatory bowel disease surgery experience of three decades. Arch Surg 1994; 129:866-9.

114 Lashner BA, Evans AA, Hanauer SB. Preoperative total parenteral nutrition for bowel resection in Crohn's disease. Dig Dis Sci 1989;34:741-6.

115 Andrews HA, Keighley MRB, Alexander-Williams J, et al. Strategy for management of distal ileal Crohn's disease. Br J Surg 1991;78:679-82.

116 Edwards CM, George BD, Jewell DP, et al. Role of a defunctioning stoma in the management of large bowel Crohn's disease. Br J Surg 2000;87:1063-6

117 Makowiec F, Jehle EC, Starlinger M. Clinical course of perianal fistulas in Crohn's disease. Gut 1995;37:696-701.

118 Scott HJ, Northover JM. Evaluation of surgery for perianal Crohn's fistulas. Dis Colon Rectum 1996;39:1039-43.

119 Yamamoto T, Bain IM, Connolly AB, et al. Gastroduodenal fistulas in Crohn's disease: clinical features and management. Dis Colon Rectum 1998;41:1287-92.

120 Fazio VW, Marchetti F, Church JM, et al. Effect of resection margins on the recurrence of Crohn's disease in the small bowel. A randomised controlled trial. Ann Surg 1996;224:563-73.

121 Yamamoto T, Bain IM, Allan RM, et al. Stapled functional end-to-end anastamosis vs sutured end-to-end anastomosis following ileocolonic resection in Crohn's disease. Scand J Gastroenterol 1999;34:708-13.

122 Stebbing JF, Jewell DP, Kettlewell MGW, et al. Long term results of recurrence and reoperation after strictureplasty for obstructive Crohn's disease. Br J Surg 1995;82:1471-4.

123 Cristaldi M, Sampietro GM, Danelli PG, et al. Long-term results and multivariate analysis of prognostic factors in 138 consecutive patients operated on for Crohn's disease using "bowel sparing" techniques. Am J Surg 2000;179:266-70.

124 Cameron JL, Hamilton SR, Coleman J, et al. Patterns of ileal recurrence in Crohn's disease. A prospective randomised study. Ann Surg 1992;215:546-52. 
125 Travis SPL. Azathioprine for prevention of postoperative recurrence in Crohn's disease. Eur J Gastroenterol Hepatol 2001;13:1277-9.

126 Korelitz B, Hanauer S, Rutgeerts P, et al. Post-operative prophylaxis with 6 MP, 5-ASA or placebo in Crohn's disease: a 2 year multicenter trial. Gastroenterology 1998;114:A1011.

127 Rutgeerts P, Hiele M, Geboes K, et al. Controlled trial of metronidazole treatment for prevention of Crohn's recurrence after ileal resection. Gastroenterology 1995;108:1617-21.

128 Sandborn W, McLeod R, Jewell DP. Pharmacotherapy for inducing and maintaining remission in pouchitis. Cochrane Database Syst Rev 2001;(2):CD001176.

129 Shepherd NA, Jass JR, Duval I, et al. Restoration proctocolectomy with ileal reservoir: a pathological histochemical study of mucosal biopsy specimens. J Clin Pathol 1987;40:601-7.

130 Mimura T, Rizzello F, Helwig U, et al. Four week open-label trial of metronidazole and ciprofloxacin for the treatment of recurrent or refractory pouchitis. Aliment Pharmacol Ther 2002;16:909-17.

131 Shen B, Achkar JP, Lashner BA, et al. A randomized trial of ciprofloxacin and metronidazole to treat acute pouchitis. Inflamm Bowel Dis 2001;7:301-5.

132 Gionchetti P, Rizello F, Venturi A, et al. Oral bacteriotherapy as maintenance treatment in patients with chronic pouchitis: a double-blind, placebo-controlled trial. Gastroenterology 2000;1 19:305-9.

133 Eaden JA, Mayberry JF. Guidelines for screening and surveillance of asymptomatic colorectal cancer in patients with inflammatory bowel disease. Gut 2002;51(Suppl 5):V10-2.

134 Ekbom A, Helmick C, Zack M, et al. Ulcerative colitis and colorectal cancer A population-based study. N Engl J Med 1990;323:1228-33.

135 Soetikno RM, Lin OS, Heidenreich PA, et al. Increased risk of colorectal neoplasia in patients with primary sclerosing cholangitis and ulcerative colitis: a meta-analysis. Gastrointest Endosc 2002;56:48-54.

136 Ullman T, Croog V, Harpaz N, et al. Progression of flat low-grade dysplasia to advanced neoplasia in patients with ulcerative colitis. Gastroenterology 2003; 125:1311-19.

137 Rutter M, Saunders B, Wilkinson K, et al. Severity of inflammation is a risk factor for colorectal neoplasia in ulcerative colitis. Gastroenterology 2004; 126:451-9.
138 Katz JA, Pore G. Inflammatory bowel disease and pregnancy. Inflamm Bowel Dis 2001;7:146-57.

139 Nørgärd B, Fonager K, Pedersen L, et al. Birth outcome in women exposed to 5-aminosalicylic acid in pregnancy: a Danish cohort study. Gut 2003:52:243-7.

140 Burke A, Lichtenstein GR, Rombeau JL. Nutrition and ulcerative colitis. Baillieres Clin Gastroenterol 1997;11:153-74.

141 Gassull MA, Cabre E. Nutrition in inflammatory bowel disease. Curr Opin Nutr Metab Care 2001:4:561-9.

142 Chintapatla S, Scott NA. Intestinal failure in complex gastrointestinal fistulae. Nutrition 2002;18:991-6.

143 Zachos M, Tondeur M, Griffiths AM. Enteral nutritional therapy for inducing remission of Crohn's disease. Cochrane Database Syst Rev $2001 ;(3): C D 000542$.

144 Fernadez-Benares F, Cabre E, Esteve-Comas M, et al. How effective is enteral nutrition in inducing remission in active Crohn's disease? A metaanalysis of the randomized cinical trials. J Parenter Enteral Nutr 1995; 19:356-64

145 Graham TO, Kandil HM. Nutritional factors in inflammatory bowel disease. Gastroenterol Clin North Am 2002;31:203-18.

146 Su CG, Judge TA, Lichtenstein GR. Extraintestinal manifestations of inflammatory bowel disease. Gastroenterol Clin North Am 2002;31:307-21.

147 Guidelines for osteoporosis in coeliac disease and inflammatory bowel disease. British Society of Gastroenterology. Gut 2000;46(Suppl 1):i1-8.

148 Loftus EV, Crowson CS, Sandborn WJ, et al. Long term fracture risk in patients with Crohn's disease: a population-based study in Olmsted County, Minnesota. Gastroenterology 2002;123:468-75.

149 Van Staa T-P, Cooper C, Brusse LS, et al. Inflammatory bowel disease and the risk of fracture. Gastroenterology 2003;125:1591-7.

150 Compston J. Osteoporosis in inflammatory bowel disease. Gut 2003;52:63-4

151 Card T, West J, Hubbard R, et al. Hip fractures in patients with inflammatory bowel disease and their relationship to corticosteroid use: a population based cohort study. Gut 2004;53:251-5.

152 Nightingale AJ, Middleton W, Middleton SJ, et al. Evaluation of the effectiveness of a specialist nurse in the management of inflammatory bowel disease. Eur J Gastroenterol Hepatol 1999;9:967-73. 